FEDERAL RESERVE BANK OF SAN FRANCISCO

WORKING PAPER SERIES

\title{
Does Quantitative Easing Affect Market Liquidity?
}

\author{
Jens H. E. Christensen \\ Federal Reserve Bank of San Francisco \\ James M. Gillan \\ University of California at Berkeley
}

December 2019

Working Paper 2013-26

http://www.frbsf.org/economic-research/publications/working-papers/2013/26/

\section{Suggested citation:}

Christensen, Jens H.E., James M. Gillan. 2019. “Does Quantitative Easing Affect Market Liquidity?” Federal Reserve Bank of San Francisco Working Paper 2013-26. https://doi.org/10.24148/wp2013-26

The views in this paper are solely the responsibility of the authors and should not be interpreted as reflecting the views of the Federal Reserve Bank of San Francisco or the Board of Governors of the Federal Reserve System. 


\title{
Does Quantitative Easing Affect Market Liquidity?
}

\author{
Jens H. E. Christensen ${ }^{\dagger}$ \\ and \\ James M. Gillan
}

\begin{abstract}
We argue that central bank large-scale asset purchases - commonly known as quantitative easing $(\mathrm{QE})$ - can reduce priced frictions to trading through a liquidity channel that operates by temporarily increasing the bargaining power of sellers in the market for the targeted securities. For evidence we analyze how the Federal Reserve's second QE program that included purchases of Treasury inflation-protected securities (TIPS) affected a measure of liquidity premiums in TIPS yields and inflation swap rates. We find that, for the duration of the program, the liquidity premium measure averaged about 10 basis points lower than expected. This suggests that QE can improve market liquidity.
\end{abstract}

JEL Classification: E43, E52, E58, G12

Keywords: unconventional monetary policy, liquidity channel, financial market frictions, TIPS, inflation swaps

We thank participants at the Second International Conference on Sovereign Bond Markets, the 2016 Annual Meeting of the American Economic Association, the 9th Annual SoFiE Conference, the 2016 Annual Meeting of the Western Finance Association, the 12th Annual Central Bank Workshop on the Microstructure of Financial Markets, and the Vienna-Copenhagen Conference on Financial Econometrics, in particular our discussants Paolo Pasquariello, Yuriy Kitsul, Cynthia Wu, and Sarah Mouabbi, as well as seminar participants at the Federal Reserve Bank of San Francisco for helpful comments. Furthermore, we are grateful to Autria Christensen, Fred Furlong, Refet Gürkaynak, Jose Lopez, and Nikola Mirkov for many helpful comments and suggestions on previous drafts of the paper. Finally, we thank Lauren Ford, Patrick Shultz, and Dori Wilson for excellent research assistance. The views in this paper are solely the responsibility of the authors and should not be interpreted as reflecting the views of the Federal Reserve Bank of San Francisco or the Federal Reserve System.

${ }^{\dagger}$ Corresponding author: Federal Reserve Bank of San Francisco, 101 Market Street MS 1130, San Francisco, CA 94105, USA; phone: 1-415-974-3115; e-mail: jens.christensen@sf.frb.org.

${ }^{\ddagger}$ Amazon Web Services; e-mail: james.gillan@berkeley.edu.

This version: November 19, 2019. 


\section{Introduction}

In response to the Great Recession induced by the global financial crisis of 2007-2009, the Federal Reserve quickly lowered its target policy rate - the overnight federal funds rateeffectively to its zero lower bound. Despite this stimulus, the outlook for economic growth remained grim and the threat of significant disinflation, if not outright deflation, was serious. As a consequence, the Fed began purchases of longer-term securities, also known as quantitative easing $(\mathrm{QE})$, as part of its new unconventional monetary policy strategy aimed at pushing down longer-term yields and providing additional stimulus to the economy.

The success of the Fed's large-scale asset purchases in reducing Treasury yields and mortgage rates appears to be well established; see Gagnon et al. (2011), Krishnamurthy and Vissing-Jorgensen (2011), and Christensen and Rudebusch (2012), among many others. These studies show that yields on longer-maturity Treasuries and other securities declined on days when the Fed announced it would increase its holdings of longer-term securities. Such announcement effects are thought to be related to the effects on market expectations about future monetary policy and declines in risk premiums on longer-term debt securities.

In this paper, we argue that it is also possible for QE programs to reduce priced frictions to trading as reflected in liquidity premiums through a liquidity channel. ${ }^{1}$ This effect comes about because the operation of a QE program is tantamount to introducing a large committed buyer into the financial markets of the securities targeted by the program. The persistent presence of the central bank in these markets increases the bargaining power of sellers relative to buyers, which, as shown by Duffie et al. (2007), can lower the liquidity premiums of these securities. By the same logic, liquidity premiums of securities not targeted by a QE program are unlikely to be affected by the liquidity channel as there is no change in the bargaining power in the markets for those securities. Moreover, while such liquidity effects in principle could persist beyond the operation of the QE program provided investors expect the central bank to extend its asset purchases in the future, they are most likely to matter when the program is in operation.

For evidence on the liquidity channel we analyze how the Fed's second QE program (henceforth QE2), which started in November 2010 and concluded in June 2011, affected the priced frictions to trading in the market for Treasury inflation-protected securities (TIPS) and the related market for inflation swap contracts. The execution of the QE2 program provides an interesting natural experiment for studying liquidity effects in these two markets because the program included repeated large purchases of TIPS. Furthermore, we show that these TIPS

\footnotetext{
${ }^{1}$ Gagnon et al. (2011) mention a liquidity, or market functioning, channel for the transmission of QE and stipulate a mechanism that shares similarities with the liquidity channel described in this paper, but they do not provide any empirical assessment of the importance of such a channel. See also Hancock and Passmore (2011) and Krishnamurthy and Vissing-Jorgensen (2011) for discussions.
} 
purchases were unique amongst the Fed's QE programs both in terms of the amounts involved and their intensity, which explains why we limit our focus to this particular QE program.

To motivate the analysis and support the view that liquidity premium reductions from the QE2 TIPS purchases could matter, we note that the existence of TIPS liquidity premiums is well established. Fleming and Krishnan (2012) report market characteristics of TIPS trading that indicate smaller trading volume, longer turnaround time, and wider bid-ask spreads than are normally observed in the regular Treasury bond market (see also Sack and Elsasser 2004, Campbell et al. 2009, Dudley et al. 2009, Gürkaynak et al. 2010, and Fleckenstein et al. 2014). However, the degree to which they bias TIPS yields remains a topic of debate because attempts to estimate TIPS liquidity premiums directly have generated varying results. ${ }^{2}$ Instead, to quantify the effects of the TIPS purchases on the functioning of the market for TIPS and the related market for inflation swaps, we use a novel measure that represents the sum of TIPS and inflation swap liquidity premiums. ${ }^{3}$ The construction of the measure only relies on the law of one price and it provides a good proxy for the priced frictions to trading in these two markets independent of the purchase program's effect on market expectations for economic fundamentals. As such, the measure is well suited to capture the changes in TIPS and inflation swap liquidity premiums that we are interested in.

Although we view the primary channel of how QE affects market liquidity as going through liquidity premiums, we note that other measures of market functioning could have been used. Kandrac and Schlusche (2013) analyze bid-ask spreads of regular Treasuries for evidence of any effects from the Treasury purchases during the various Fed QE programs, but do not find any significant results. Thus, they conclude that these purchases had no effect on the functioning of the Treasury bond market. In terms of the market for TIPS, the series of TIPS bid-ask spreads available to us do not appear to be reliable with many stale quotes as shown in online appendix A. Thus, we do not pursue an analysis similar to theirs. Fleming and Sporn (2013) study trading activity, quote incidences, and other indicators of market activity in the inflation swap market. We choose to focus on our liquidity premium measure because it quantifies the frictions to trading in the TIPS and inflation swap markets as a yield difference rather than as quantities.

Still, it remains the case that QE may reduce the frictions to trading in a broader sense. As a consequence, we explore the impact on TIPS trading volumes in our empirical analysis and find positive, but insignificant effects. However, we acknowledge that, in general, large-scale asset purchases such as the QE2 program have the potential to impair market functioning by

\footnotetext{
${ }^{2}$ Abrahams et al. (2016), Pflueger and Viceira (2016), and D'Amico et al. (2018) are among the studies that estimate TIPS liquidity premiums.

${ }^{3}$ As a derivative whose pricing is tied to TIPS, inflation swaps contain their own liquidity premiums. However, these premiums appear to be small compared to those in the TIPS market due to the fact that inflation swaps involve no exchange of money at inception, see Driessen et al. (2016) and Fleckenstein et al. (2014) for evidence and discussions.
} 
reducing the amount of securities available for trading. D'Amico et al. (2018) document that the Fed's Treasury purchases from March 2009 to December 2012-hence encompassing the QE2 program-lowered the repo rates and raised the prices of targeted Treasury securities through a scarcity channel, while Kandrac (2013, 2018) provides evidence of negative effects on market functioning in the context of the Fed's purchases of mortgage-backed securities. In our case, though, the Fed's TIPS purchases during QE2 were not overly concentrated in any specific TIPS (as we document), and therefore there is little reason to suspect that this effect played any major role during the period under analysis, and our results are consistent with this view.

To estimate the effect of the TIPS purchases during QE2 on our liquidity premium measure, we use a selection on observables strategy to control for potentially confounding variation that may have occurred over the course of the program. Our empirical strategy identifies the change in the mean liquidity premium during the program conditional on our set of controls and finds a significant effect across various sample period definitions and control specifications. Specifically, to determine the change in the conditional mean, we estimate a linear regression with our liquidity measure and a set of lagged controls to flexibly allow for autoregressive persistence in the relationship. In addition, we estimate an event-study specification that quantifies the change in the conditional mean relative to the 8 weeks prior to the launch of the QE2 program. Decomposing the estimates week by week, we document a U-shaped pattern in the effect that peaks during the middle of the program at 20 basis points and returns to pre-program levels towards the end, suggestive of a short-lived cumulative effect of the TIPS purchases that shares similarities with the on-the-run premium phenomenon in the Treasury market and is consistent with the theoretical workings of the liquidity channel as described earlier. Furthermore, we employ a randomization inference strategy to test whether our results are an artifact of our model specification. To do this, we estimate changes in the conditional mean for "placebo" periods of the same length as the QE2 program, which generates a distribution of estimates. The mean of these distributions is close to zero, and our estimate for the true QE2 program period is more negative than 90 percent of the placebo treatment periods, which confirms the significance of our results. As a final robustness check and to dispel concerns that the detected effects are caused by changes in the liquidity of inflation swaps rather than TIPS, we repeat the analysis with the average liquidity premiums of 5- and 10-year TIPS estimated by Andreasen et al. (2018) and obtain qualitatively similar results. Taken together, these results suggest that, for the duration of the QE2 program, the liquidity premium measure averaged about 10 basis points lower than expected, a reduction of almost 50 percent from pre-QE2 levels. We interpret these findings as indicating that part of the effect from QE programs derives from improvements in the market conditions for the targeted securities as reflected in liquidity premiums. 
To assess whether the liquidity channel affects liquidity premiums of securities not targeted by the QE2 program, we repeat the analysis using credit spreads of AAA-rated industrial corporate bonds, an asset class the Fed under normal circumstances is not allowed to acquire and hence could not possibly be expected to purchase. ${ }^{4}$ As the default risk of such highly rated bonds is negligible, their credit spreads mostly represent liquidity premiums. ${ }^{5}$ Consistent with the theory of the liquidity channel, which emphasizes QE programs' effects on the liquidity conditions of the targeted securities, we obtain no significant results in this exercise. Although not conclusive as we only consider one alternative asset class, we take this as evidence that the transmission of the liquidity channel is indeed limited to the purchased security classes.

D'Amico and King (2013, henceforth DK) emphasize local supply effects as an important mechanism for QE to affect long-term interest rates. Under this local supply channel declines in the stock of government debt available for trading induced by QE purchases should push up bond prices (temporarily) due to preferred habitat behavior on the part of investors. To analyze whether our results could be driven by local supply effects, we replicate the approach of DK to detect effects on individual TIPS prices from the TIPS purchases in the QE2 program. However, we fail to get any significant results, which suggests that local supply effects are not likely to be able to account for our findings.

To the best of our knowledge, this paper is the first to study the liquidity channel as a separate transmission mechanism for QE to affect long-term interest rates and to document that such liquidity effects are distinct from and more persistent than the local supply channel highlighted in the existing literature. ${ }^{6}$

In related research, De Pooter et al. (2018) analyze the government bond purchases performed by the European Central Bank (ECB) as part of its Securities Markets Programme (SMP) that operated from May 2010 to March 2012. To avoid assessing changes to expectations about monetary policy, they scrutinize the spreads between yields of targeted government bonds from the euro-area periphery and non-targeted German bund yields and control for credit risk using CDS rates. This leaves them with a measure of priced frictions that is very similar in concept to ours. In the empirical analysis, they report instantaneous effects on the order of 30-40 basis points from purchasing one percent of the outstanding market, while their results reveal longer lasting effects of 13 to 17 basis points. In light of our study, we interpret the difference of about 25 basis points between their two results as representing local supply effects of the nature discussed in DK, while the lasting effects of about 15 basis points can be taken to represent an estimate of the importance of the liquidity channel and

\footnotetext{
${ }^{4}$ See Section 14 of the Federal Reserve Act.

${ }^{5}$ See Collin-Dufresne et al. (2001) for evidence and a discussion of the weak link between corporate bond credit spreads and their default risk, frequently referred to as the credit spread puzzle, and Christensen (2008) for an overview of related research.

${ }^{6}$ This paper represents the completion of the preliminary analysis described in Christensen and Gillan (2012).
} 


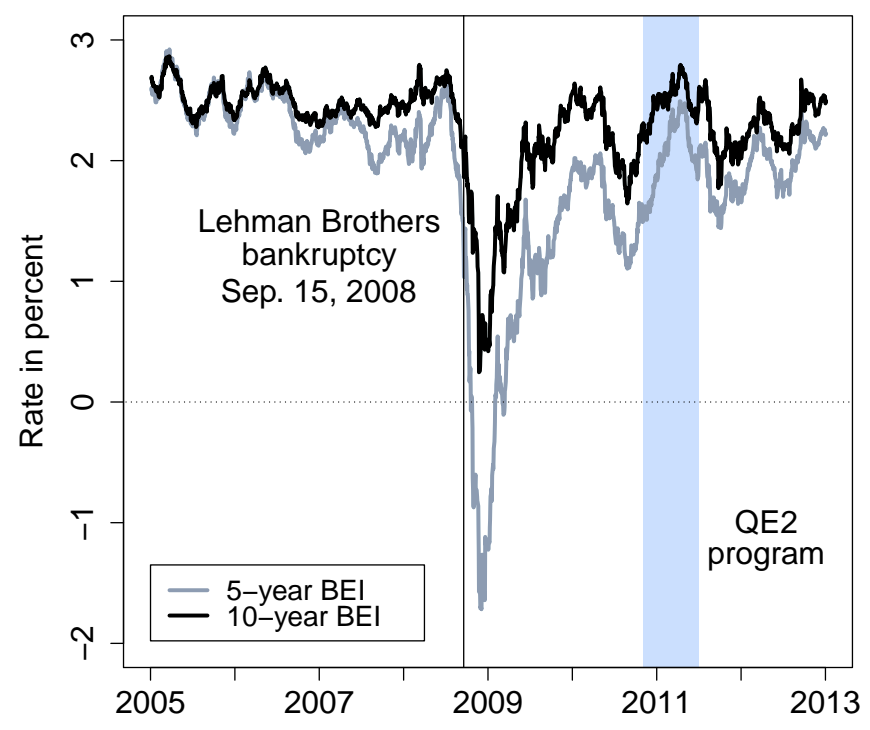

Figure 1: TIPS Breakeven Inflation

are remarkably similar in magnitude to our results for the TIPS market. Eser and Schwaab (2016) also study instantaneous purchase effects from the ECB's SMP and report results of comparable magnitudes. In their own interpretation, reduced liquidity premiums appear to be the most important factor behind their findings.

Our findings could have important policy implications. First, for assessing the credibility of the Fed's price stability goal, it is a common practice to study the difference in yield between regular Treasury bonds and TIPS of the same maturity, known as breakeven inflation (BEI), which represent market-based measures of inflation compensation frequently mentioned in FOMC statements. Figure 1 shows daily 5- and 10-year BEI since 2005, also highlighted is the operation of the QE2 program. During the period of its operation, BEI first experienced a sharp increase until the middle of the program followed by a notable downtick towards its end. Specifically, at the 5-year maturity, BEI started at 1.51\% on November 3, 2010, peaked at $2.49 \%$ on April 8, 2011, before retracing to $2.07 \%$ by the end of June 2011. At the 10year maturity, BEI increased from $2.30 \%$ to $2.78 \%$ and fell back down to $2.59 \%$ between the same three dates. Based on our results, as much as one-third of the variation in BEI during this period could reflect effects arising from the QE2 TIPS purchases through the liquidity channel that, by definition, would have little to do with investors' inflation expectations or associated inflation risk premiums. ${ }^{7}$ Thus, in determining how much the QE2 program helped

\footnotetext{
${ }^{7}$ For the maximum effect of the liquidity channel on BEI to apply, it must be the case that there was no
} 
boost investors' inflation expectations, it is crucial to account for the effects of the liquidity channel.

More generally, for central banks in countries with somewhat illiquid sovereign bond markets (most euro-area countries likely belong in this category as suggested by the analysis in De Pooter et al. 2018), QE programs that target sovereign debt securities could be expected to reduce the liquidity premiums of those securities quite notably for the duration of the programs, which might be worthwhile to keep in mind when evaluating the effects of such QE programs. In this regard, we note that the TIPS market with a total outstanding notional of $\$ 1,245$ billion as of the end of 2016 is quite comparable to the major European sovereign bond markets. Thus, our analysis could provide a useful reference point for understanding the effects of the liquidity channel in the European context.

Finally, since the Fed's TIPS purchases represented less than five percent of the TIPS market, our results suggest that even relatively modest QE programs could have sizable effects when the targeted security classes contain some amount of liquidity risk. ${ }^{8}$ Thus, the significance of the liquidity channel could matter for the design of QE programs; time frame, purchase pace, and targeted security classes are all decision variables that merit careful consideration under those circumstances.

The remainder of the paper is structured as follows. Section 2 discusses the channels of transmission of $\mathrm{QE}$ to long-term interest rates, paying special attention to the proposed liquidity channel. Section 3 details the execution of the TIPS purchases included in the QE2 program, while Section 4 describes the construction of the TIPS and inflation swap liquidity premium measure. Section 5 introduces the econometric model we use and presents our results. Section 6 concludes the paper and provides directions for future research. Appendices available online contain details about TIPS bid-ask spreads, an event study of QE2 announcement effects, a description of our adaptation of DK's approach, a preliminary regression analysis with indicator variables for the Fed's four asset purchase programs, and a comparison of our liquidity premium measure to asset swap spreads.

\section{Transmission Channels of QE to Long-Term Rates}

In this section, we first give a theoretical overview of how to think about QE and its effects on the economy before we discuss the mechanics of the liquidity channel we highlight.

change in the liquidity premiums of inflation swaps in response to the QE2 TIPS purchases, a possibility our analysis allows for.

${ }^{8}$ The large effects on mortgage rates of the Fed's purchases of mortgage-backed securities during its first large-scale asset purchase program, which Krishnamurthy and Vissing-Jorgensen (2011) partly attribute to improved market functioning and reduced liquidity premiums, provide another example. 


\subsection{Theoretical Overview}

Once a central bank has reduced its leading conventional policy rate to its effective lower bound, it may be forced to engage in QE to provide further monetary stimulus, if needed. This has been the reality facing several of the world's most prominent central banks in recent years.

The main mechanism for QE to affect the real economy is through its impact on longterm interest rates, which are key variables in determining many important economic decisions ranging from firm investment on the business side to home and auto purchases on the household side of the economy. Therefore, to understand how QE works, we need to study its transmission channels to long-term interest rates.

The most straightforward way QE can affect long-term interest rates is by acting as a signaling device that changes agents' expectations about the future path for monetary policy. Christensen and Rudebusch (2012) and Bauer and Rudebusch (2014) are among the studies that emphasize the importance of the signaling channel for understanding the effects of QE.

Beyond potential signaling effects that would affect the yields of all securities, QE programs may change the supply of or demand for a given asset, which could affect its price and hence risk premium. Such effects are usually referred to as portfolio balance effects. ${ }^{9}$

\subsection{The Liquidity Channel}

The channel we emphasize in this paper is for QE to have effects on the liquidity premiums that investors demand to hold any security that is less than perfectly liquid. ${ }^{10}$ To be specific, we think of the liquidity premium of a security as representing investors' required compensation for assuming the risk of having to liquidate a long position in the security prematurely at a potentially depressed price, say, in a stressed market environment when market makers and arbitrageurs are severely capital constrained. We note that under normal circumstances the liquidity premium is determined as the outcome of a non-cooperative game between buyers and sellers and embeds their collective assessment of the net present value of the total sum of frictions to trading until maturity.

When a central bank launches a QE program, we argue that it is equivalent to introducing into financial markets a committed buyer with deep pockets. A potential consequence of the persistent market presence of the central bank is that it may change the outcome of the game that determines the liquidity premiums for the targeted securities. To see this, note that market participants as rational agents are aware of the fact that, when confronted with

\footnotetext{
${ }^{9}$ See Christensen and Krogstrup $(2018,2019)$ for a detailed discussion of various forms of portfolio balance effects.

${ }^{10} \mathrm{~A}$ perfectly liquid security can be sold any time in arbitrarily small or large amounts at no trading costs (i.e., there is no bid-ask spread) and without affecting its price. A demand deposit is close to meeting these requirements if we abstract from the default risk of large deposits, which are not government guaranteed.
} 
disadvantageous price offers in the market, sellers can pursue the alternative strategy of submitting bids in the QE purchase auctions and sell securities targeted by a QE program that way. As a result, the presence and actions of the central bank tilt the bargaining power away from buyers and towards sellers in the markets for the securities targeted by the QE asset purchases. As demonstrated by Duffie et al. (2007), increased bargaining power of sellers can reduce the search-and-bargaining frictions in over-the-counter markets such as the TIPS market and lead to reduced illiquidity price discounts in equilibrium. In short, sellers are less likely to be significantly squeezed while the QE program is in operation, which makes all market participants willing to accept a lower liquidity premium.

In terms of dynamic profile, we note that the effects of the liquidity channel should taper off towards the end of a QE program as the number of remaining purchase auctions goes to zero since market participants would be left playing their normal non-cooperative game once the program has ended. We think of this as similar in structure to the on-the-run phenomenon in the Treasury market where so-called on-ten-run premiums for newly issued Treasuries caused by their extreme liquidity tend to dissipate as the securities approach the known time when they go off-the-run and become less liquid because new securities have been issued, see Goldreich et al. (2005) for evidence in terms of 2-year Treasury notes. However, unlike Treasury auctions, which are frequent and therefore lead to well-known patterns for onthe-run premiums, investors had little experience with QE purchases of TIPS at the time of the launch of the QE2 program. As a consequence, it may have taken a few auctions for investors to fully assess the extent to which the TIPS purchases would tilt bargaining power towards sellers in the TIPS market. In general, this suggests that effects tied to the liquidity channel could have a different dynamic profile than effects from other QE transmission channels, in particular announcement effects are not necessarily material in size for the liquidity channel.

Furthermore, we stress that the liquidity channel is distinct from the insurance against macroeconomic tail risks that central bank asset purchases could potentially provide as discussed in Hattori et al. (2016). While the latter channel also affects the downside risk of assets, it is economy-wide in nature and would impact all asset classes instantaneously upon announcement thanks to the forward-looking behavior of investors, and we control for such announcement effects in our analysis as detailed in the section below.

The importance of the liquidity channel for a given security class is likely to be determined by several factors. First, its effect should be positively correlated with the amount purchased relative to the total market value of the security class. Second, the intensity of the purchases, that is, the length of time it takes to purchase a given amount, could play a role as well. The more intense the purchases are, the greater is the ability of a given QE program to absorb negative liquidity shocks that force owners of targeted securities to sell and exert downward pressure on the securities' prices. As a consequence, the reduction in liquidity 
premiums should have a positive correlation with the purchase pace. Furthermore, the size of the liquidity premiums in the targeted security classes should matter. Since such liquidity premiums are widely perceived to be small in the deep and liquid Treasury bond market, it may explain why the liquidity channel has received little attention in the existing literature.

Finally, it is important to emphasize that, for the liquidity channel and the associated liquidity effects to exist, no portfolio balance effects are needed; only financial market frictions are required. Ultimately, the existence and importance of the liquidity channel may be tied to theories of limits to arbitrage capital with market makers and arbitrageurs; see $\mathrm{Hu}$ et al. (2013, henceforth HPW) for a discussion. ${ }^{11}$ However, we leave it for future research to establish any such ties.

\subsection{Identification of Liquidity Effects}

In order to empirically identify effects on long-term interest rates arising through the liquidity channel, two criteria must be met. First, we need a QE program that is large, includes repeated purchases of securities less liquid than Treasuries, and operates over a period long enough that the fears of forced resales implicit in the definition of liquidity premiums can be meaningfully affected by the purchases. Second, we must have a suitable measure of the priced frictions in the markets for the purchased securities.

The Fed's QE2 program meets these criteria. First, this program was large, operated over an eight-month period, and included repeated purchases of a significant amount of TIPS, which are widely perceived to be less liquid than Treasuries as already argued. Second, we devise a measure of the priced frictions in TIPS yields and inflation swap rates detailed in Section 4 that we use to detect evidence of the liquidity channel. Still, in trying to identify effects from the liquidity channel, we acknowledge that signaling, portfolio balance, and local supply effects could be operating as well.

In principle, effects of the signaling and portfolio balance channels should materialize immediately following the announcement of the QE2 program and not when it is implemented thanks to the rational, forward-looking behavior of investors. As a consequence, we look for effects related to the announcement of the program on November 3, 2010, but fail to detect any significant yield responses as documented in online appendix B. More likely, announcement effects tied to these channels materialized in the weeks and months ahead of the launch of the QE2 program as argued by Krishnamurthy and Vissing-Jorgensen (2011). Moreover, the signaling and portfolio balance channels are thought to mainly affect the policy expectations and term premium components of bond prices, which should cancel out in the construction of our liquidity premium measure. Thus, neither of these channels are likely to be the drivers

\footnotetext{
${ }^{11}$ Brunnermeier and Pedersen (2009) and Pasquariello (2018) provide examples of theoretical models where funding liquidity and informational frictions, respectively, may affect the workings of financial markets.
} 
of our results. Also, it follows from this discussion that, in case there are unaccounted announcement effects, our results will be conservative and represent lower bound estimates of the importance of the liquidity channel.

To address the local supply channel, we replicate the analysis of DK in an attempt to identify local supply effects in individual TIPS prices, but fail to get any significant results as documented in online appendix C. Importantly, the mechanics of the liquidity channel suggest that its effects are not limited to any specific security, but would apply to all securities at risk of being targeted by the QE program, which contrasts with the type of analysis performed by DK that focuses on identifying local supply effects in individual security prices on purchase operation dates.

With signaling, portfolio balance, and local supply channels ruled out as important drivers of the variation in our measure of liquidity premiums in TIPS yields and inflation swap rates during the QE2 program, we turn our focus to the proposed liquidity channel. The remainder of the paper is dedicated to analyzing whether the TIPS purchases in the QE2 program had any effects on our liquidity premium measure consistent with this channel.

\section{The TIPS Purchases in the QE2 Program}

In this section, we provide a brief description of the Federal Reserve's QE2 program, which included purchases of a sizable amount of TIPS.

The QE2 program was announced on November 3, 2010. In its statement, the Federal Open Market Committee (FOMC) said that the program would expand the Fed's balance sheet by $\$ 600$ billion through Treasury security purchases over approximately an eight-month period. In addition, the FOMC had already decided in August 2010 to reinvest principal payments on its portfolio of agency debt and mortgage-backed securities in longer-term Treasury securities in order to maintain the size of the Fed's balance sheet, a policy that was maintained until September 2011. ${ }^{12}$ As a consequence, the gross purchases of Treasury securities from November 3, 2010, until June 29, 2011, totaled nearly $\$ 750$ billion, of which TIPS purchases represented about $\$ 26$ billion. Since the total amount of marketable Treasury debt increased by $\$ 792$ billion between the end of October 2010 and the end of June 2011, the Fed's Treasury purchases during this period nearly kept pace with the Treasury net issuance. In terms of TIPS, though, the net supply increased by $\$ 61$ billion so that the Fed's purchases only represented an amount equal to 42 percent of the new supply. Thus, in the aggregate, the Fed's TIPS purchases did not come at the expense of private sector holdings.

The uniqueness of these TIPS purchases is evident in Figure 2(a), which shows the total

\footnotetext{
${ }^{12}$ The Fed has all along reinvested principal payments on its portfolio of Treasury securities in Treasuries. Since September 2011, the Fed has been reinvesting principal payments on its portfolio of agency debt and mortgage-backed securities in agency mortgage-backed securities to support the housing market.
} 


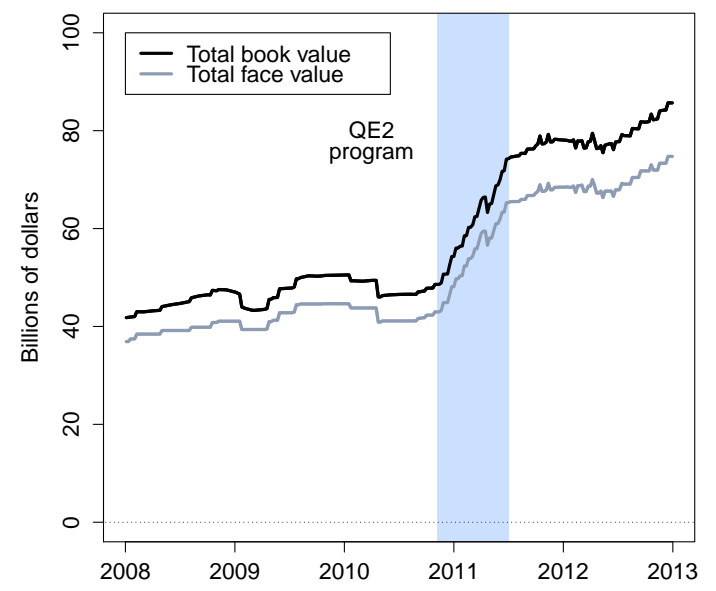

(a) Value of TIPS

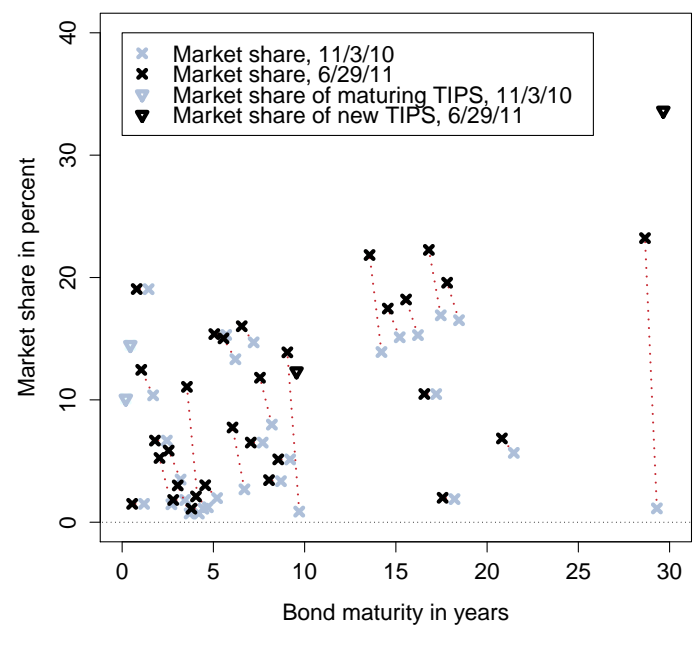

(b) Share of TIPS market

Figure 2: Fed's TIPS Holdings

Panel (a) shows the total book and face value of TIPS held in the Federal Reserve System's Open Market Account (SOMA). The difference between the two series reflects accrued inflation compensation. The data are weekly covering the period from January 2, 2008, to December 26, 2012. Panel (b) shows the market share of individual TIPS held by the Fed at the start of QE2 and at its conclusion with thin dashed red lines indicating the change in the shares held. Note that two TIPS held as of November 3, 2011, matured before the end of the program, and two new TIPS were issued during the program and acquired by the Fed.

book value of the Fed's TIPS holdings from 2008 to 2012. They increased the Fed's holdings by 52.8 percent and brought the total close to $\$ 75$ billion. ${ }^{13}$ Figure $2(\mathrm{~b})$ shows the market share of individual TIPS held by the Fed at the beginning of the QE2 program and at its conclusion with thin dashed red lines indicating the change for each TIPS. A total of three TIPS were issued during the QE2 program; the 5-year 4/15/2016 TIPS issued on April 29, 2011, the 10-year 1/15/2021 TIPS issued on January 31, 2011, and the 30-year 2/15/2041 TIPS issued on February 28, 2011. As of June 29, 2011, the Fed was only holding the two latter securities shown with black triangles in Figure 2(b). Note that the purchases were not heavily concentrated in any particular TIPS, and the Fed's TIPS holdings as a percentage of the stock of each security in general remained well below one-third.

The QE2 program was implemented with a very regular schedule. Once a month, the Fed publicly released a list of operation dates for the following 30-plus day period, indicating the relevant maturity range and expected purchase amount for each operation. There were 15 separate TIPS operation dates, fairly evenly distributed across time, each with a stated expected purchase amount of $\$ 1$ billion to $\$ 2$ billion. Table 1 lists the 15 operation dates, the

\footnotetext{
${ }^{13}$ The slight decline in mid-April 2011 is due to a maturing 5 -year TIPS of which the Fed was holding $\$ 2.9$ billion in principal and $\$ 327$ million in accrued inflation compensation.
} 


\begin{tabular}{|l||c||c|}
\hline $\begin{array}{l}\text { QE2 TIPS purchase } \\
\text { operation dates }\end{array}$ & $\begin{array}{c}\text { TIPS } \\
\text { purchases } \\
\text { (mill.) }\end{array}$ & $\begin{array}{c}\text { Weighted avg. } \\
\text { maturity } \\
\text { (years) }\end{array}$ \\
\hline \hline (1) Nov. 23, 2010 & $\$ 1,821$ & 9.43 \\
(2) Dec. 8, 2010 & $\$ 1,778$ & 8.88 \\
(3) Dec. 21, 2010 & $\$ 1,725$ & 16.09 \\
(4) Jan. 4, 2011 & $\$ 1,729$ & 16.98 \\
(5) Jan. 18, 2011 & $\$ 1,812$ & 14.64 \\
(6) Feb. 1, 2011 & $\$ 1,831$ & 13.58 \\
(7) Feb. 14, 2011 & $\$ 1,589$ & 14.16 \\
(8) Mar. 4, 2011 & $\$ 1,589$ & 11.37 \\
(9) Mar. 18, 2011 & $\$ 1,653$ & 17.77 \\
(10) Mar. 29, 2011 & $\$ 1,640$ & 18.29 \\
(11) Apr. 20, 2011 & $\$ 1,729$ & 23.17 \\
(12) May 4, 2011 & $\$ 1,679$ & 13.62 \\
(13) May 16, 2011 & $\$ 1,660$ & 20.49 \\
(14) Jun. 7, 2011 & $\$ 1,589$ & 14.30 \\
(15) Jun. 17, 2011 & $\$ 2,129$ & 5.98 \\
\hline Average & $\$ 1,730$ & 14.58 \\
\hline
\end{tabular}

Table 1: QE2 TIPS Purchase Operations

The table reports the amount and weighted average maturity of TIPS purchased on the 15 TIPS operation dates during the QE2 program.

total purchase amounts, and the weighted average maturity of the TIPS purchased. TIPS were the only type of security acquired on these dates, and the Fed did not buy any TIPS outside of those dates over the course of the program. ${ }^{14}$ Furthermore, all outstanding TIPS with a minimum of two years remaining to maturity were eligible for purchase on each operation date and, as shown in Figure 2(b), the Fed did purchase TIPS across the entire indicated maturity range. Thus, there does not appear to be a need to account for price movements of specific securities related to the release of the operation schedules. Also, market participants did not know in advance either the total amount to be purchased or the distribution of the purchases. However, since the actual purchase amounts all fall in the range from $\$ 1.589$ billion to $\$ 2.129$ billion, investors' perceived uncertainty about the total purchase amounts likely was lower than the width of the indicated range. Finally, the auction results containing this information were released a few minutes after each auction. As the auctions closed at 11:00 a.m. Eastern time, investors had sufficient time to process the information before the close of the market on each operation date. It is this structure of the execution of the TIPS purchases in the QE2 program that makes it a natural candidate for detecting local supply effects in individual

\footnotetext{
${ }^{14}$ Also, there were no TIPS auctions by the U.S. Treasury on any of the Fed's 15 TIPS operation dates. See Lou et al. (2013) for analysis of the effects of auctions in the regular nominal Treasury bond market.
} 


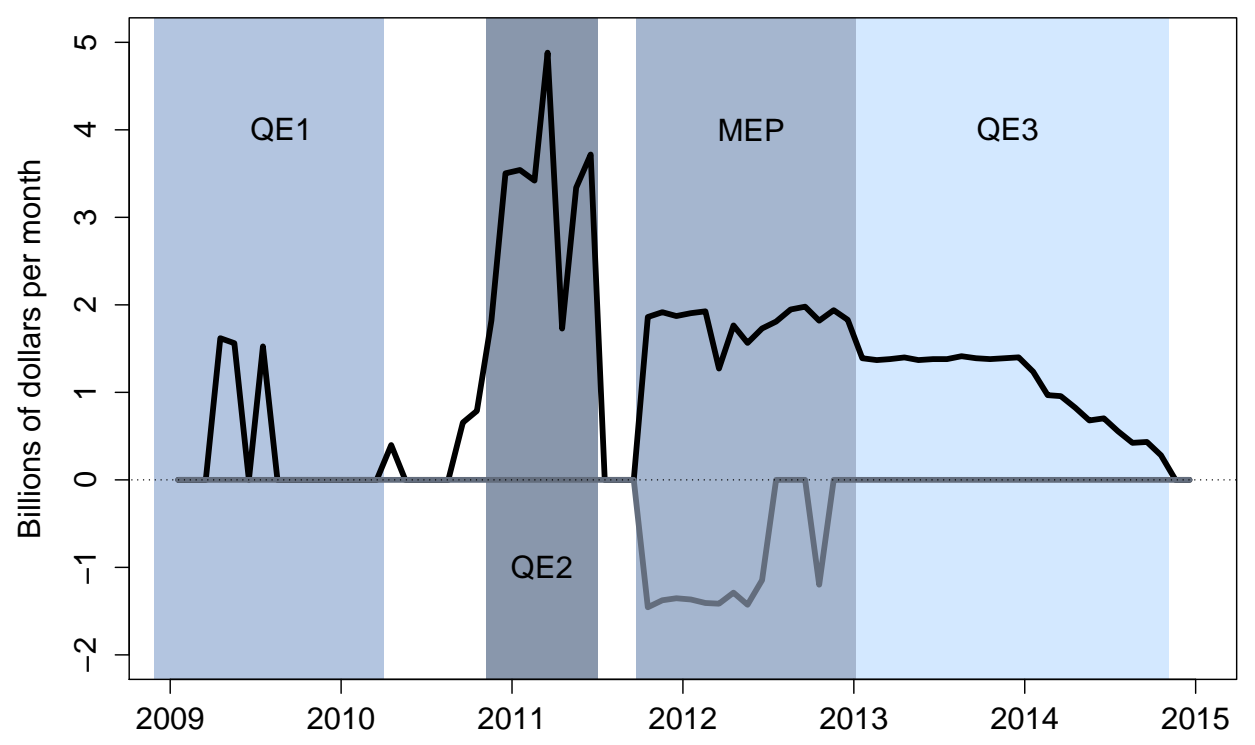

Figure 3: Fed TIPS Purchases and Sales

TIPS prices as we attempt in online appendix C.

To put the QE2 TIPS purchases in the context of other TIPS transactions performed by the Fed as part of its QE programs, Figure 3 shows the Fed's monthly TIPS purchases (solid black line) and sales (solid grey line) in billions of dollars from November 2008 through December 2014. Also indicated in different shades of grey are the Fed's four program periods. A number of observations are worth highlighting with regard to our analysis. First and most importantly, the QE2 program stands out as the largest and by far most intense in terms of monthly TIPS purchases, which matters for the strength of the liquidity channel that we want to study. ${ }^{15}$ Second, during the Fed's first QE program (QE1) and the following reinvestment period when principal payments on the Fed's MBS holdings were rolled into Treasuries and TIPS, TIPS purchases were small and spotty. Third, the Maturity Extension Program (MEP) that came after QE2 included both purchases of long-term TIPS and sales of shorter-term TIPS leaving the net purchases relatively small as intended since the aim of the MEP was not to expand the Fed's balance sheet, but merely to change its composition. Finally, the Fed's last QE program, known as QE3, included an amount of TIPS purchases comparable to those under QE2 but stretched out over a much longer time period. As a consequence, these purchases were much less intense and hence offered less liquidity risk absorbing capacity for

\footnotetext{
${ }^{15}$ Chakraborty et al. (2017) use quarterly changes in the Fed's balance sheet as a measure of the intensity of its respective QE programs.
} 
investors in the TIPS market than the QE2 program.

To support the view that the Fed's QE2 program was the strongest and most intense QE program targeting the TIPS market, we perform a preliminary regression analysis with indicator variables for the Fed's four asset purchase programs using our liquidity premium measure introduced below as the dependent variable. The results reported in online appendix D show that indeed only the Fed's QE2 program yield statistically significant results. Therefore, in the remainder of the paper, we limit our focus to that program.

\section{A Measure of Liquidity Premiums in TIPS and Inflation Swaps}

In this section, we describe the measure of liquidity premiums in TIPS yields and inflation swap rates that we use as a dependent variable in our empirical analysis.

Ideally, we would like to use a pure measure of liquidity premiums in TIPS yields in our analysis. However, empirically, it is very challenging to separate liquidity premiums from other factors that affect TIPS yields such as expectations for monetary policy and inflation, although we do consider such a measure for robustness in Section 5.6. Instead, we combine the information in Treasury yields, TIPS yields, and inflation swap rates to get a handle on the size of the liquidity premiums in TIPS yields and inflation swap rates jointly as explained in the following.

To begin, note that, unlike regular Treasury securities that pay fixed coupons and a fixed nominal amount at maturity, TIPS deliver a real payoff because their principal and coupon payments are adjusted for inflation based on the consumer price index (CPI). The difference in yield between regular nominal, or non-indexed, Treasury bonds and TIPS of the same maturity is referred to as breakeven inflation, since it is the level of inflation that makes investments in indexed and non-indexed bonds equally profitable.

In an inflation swap contract, the owner of a long position pays a fixed premium in exchange for a floating payment equal to the change in the CPI. At inception, the fixed premium is set such that the contract has a value of zero.

Since the cash flows of TIPS and inflation swaps are both adjusted using the CPI, economic theory implies a connection between their pricing. Specifically, in a frictionless world, the absence of arbitrage opportunities requires the inflation swap rate to equal BEI because buying one nominal discount bond today with a given maturity produces the same cash flow as buying one real discount bond of the same maturity and selling an inflation swap contract also of the same maturity. However, in reality, the trading of both TIPS and inflation swaps is impeded by frictions, such as wider bid-ask spreads and less liquidity relative to the market for regular nominal Treasury bonds. As a consequence, the difference between inflation swap 
rates and BEI will not be zero, but instead represents a measure of how far these markets are from the frictionless outcome described above. ${ }^{16}$

To map this to our data, we observe a set of nominal and real Treasury zero-coupon bond yields denoted $\widehat{y}_{t}^{N}(\tau)$ and $\widehat{y}_{t}^{R}(\tau)$, respectively, where $\tau$ is the number of years to maturity. Also, we observe a corresponding set of rates on zero-coupon inflation swap contracts denoted $\widehat{I S}_{t}(\tau)$. As noted above, these rates differ from the unobserved values that would prevail in a frictionless world without any obstacles to continuous trading denoted $y_{t}^{N}(\tau), y_{t}^{R}(\tau)$, and $I S_{t}(\tau)$, respectively, with the theoretical relationship:

$$
I S_{t}(\tau)=y_{t}^{N}(\tau)-y_{t}^{R}(\tau)
$$

Now, we make three fundamental assumptions:

(1) The nominal Treasury yields we observe are very close to the unobservable frictionless nominal yields, that is, $\widehat{y}_{t}^{N}(\tau)=y_{t}^{N}(\tau)$ for all $t$ and all relevant $\tau$. Even if not exactly true (say, for example, during the financial crisis), this is not critical as the point is ultimately about the relative liquidity between securities that pay nominal and real yields.

(2) TIPS are no more liquid than nominal Treasury bonds. As a consequence, TIPS yields contain a time-varying liquidity premium denoted $\delta_{t}^{R}(\tau)$, which generates a wedge between the observed TIPS yields and their frictionless counterpart given by $\widehat{y}_{t}^{R}(\tau)=y_{t}^{R}(\tau)+\delta_{t}^{R}(\tau)$ with $\delta_{t}^{R}(\tau) \geq 0$ for all $t$ and all relevant $\tau$.

(3) Inflation swaps are no more liquid than nominal Treasury bonds. Hence, the observed inflation swap rates are also different from their frictionless counterpart with the difference given by $\widehat{I S}_{t}(\tau)=I S_{t}(\tau)+\delta_{t}^{I S}(\tau)$ and $\delta_{t}^{I S}(\tau) \geq 0$ for all $t$ and all relevant $\tau$.

In support of these assumptions, we note that market size, trading volume, and bid-ask spreads all indicate that regular Treasury securities are much more liquid than both TIPS and inflation swaps. It then follows that the difference between observed inflation swap and BEI rates, which defines our liquidity premium measure, is given by

$$
\begin{aligned}
L P_{t}(\tau) & \equiv \widehat{I S}_{t}(\tau)-\widehat{B E I}_{t}(\tau) \\
& =\widehat{I S}_{t}(\tau)-\left[\widehat{y}_{t}^{N}(\tau)-\widehat{y}_{t}^{R}(\tau)\right] \\
& =I S_{t}(\tau)+\delta_{t}^{I S}(\tau)-\left[y_{t}^{N}(\tau)-\left(y_{t}^{R}(\tau)+\delta_{t}^{R}(\tau)\right)\right] \\
& =\delta_{t}^{R}(\tau)+\delta_{t}^{I S}(\tau) \geq 0
\end{aligned}
$$

\footnotetext{
${ }^{16}$ Note that, due to collateral posting, the credit risk in inflation swap contracts is negligible and can be neglected for pricing purposes. Also, we assume the default risk of the U.S. government to be negligible, and even if not exactly true, any material credit risk premium is unlikely to bias our measure as it would presumably affect Treasury and TIPS yields in the same way, leaving BEI effectively unchanged.
} 


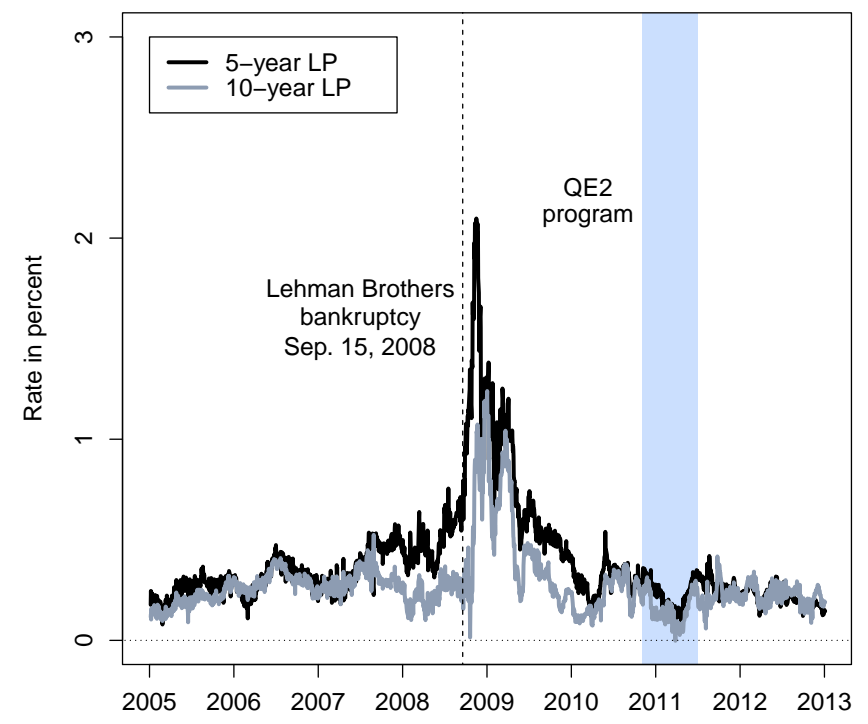

Figure 4: Sum of Liquidity Premiums in TIPS and Inflation Swaps

This shows that $L P_{t}(\tau)$ is nonnegative and equal to the sum of liquidity premiums in TIPS yields and inflation swap rates. Hence, $L P_{t}(\tau)$ quantifies how far the observed market rates are from the frictionless outcome. We note that Fleckenstein et al. (2014) also rely on these relationships to document systematic underpricing of TIPS.

\subsection{Construction of the Liquidity Premium Measure}

We use daily zero-coupon nominal and real Treasury bond yields as constructed by Gürkaynak et al. $(2007,2010)$ for our observed bond yields. ${ }^{17}$ For the inflation swap rates, we use daily quotes from Bloomberg. These rates are for zero-coupon inflation swap contracts, meaning they have no exchange of payment upon issuance and a single cash flow exchanged at maturity. The quoted rates represent the payment of the fixed leg at an annual rate, which we convert into continuously compounded rates using the formula $\widehat{I S}_{t}^{c}(\tau)=\ln \left(1+\widehat{I S}_{t}(\tau)\right)$ to make them comparable to the other interest rates. Bloomberg begins reporting quotes on inflation swap rates in early 2004, but the data are not densely populated until the end of the year. As a result, we begin the sample period on January 4, 2005, and end it on December 31, 2012. Finally, we eliminate the few days where quotes are not available for all maturities, which leaves us with a sample of 1,977 observations.

\footnotetext{
${ }^{17}$ Even though these yields are constructed using the Svensson (1995) yield curve model, their robust estimation makes them essentially model-free.
} 
Figure 4 shows $L P_{t}(\tau)$ at the 5 - and 10-year maturity. In the empirical analysis, we aim to quantify the liquidity effects of the QE2 TIPS purchases on the priced frictions in the markets for TIPS and inflation swaps as reflected in our liquidity premium measure. Importantly, in the construction of the measure, any effects of the QE2 program on bond investors' views of economic fundamentals, such as future monetary policy, inflation, and their implications for bond yields, will cancel out as they affect inflation swap rates and BEI of the same maturity equally. This is also the reason why the measure is likely affected to a minimum by signaling and portfolio balance effects.

We note that other model-free measures of priced frictions could have been used. One such alternative measure can be constructed from asset swap spreads as described in Pflueger and Viceira (2016). In online appendix E, we demonstrate that, in theory, this measure should be closely correlated with our liquidity premium measure and we make a brief comparison of the two and find them to be highly positively correlated. This suggests that the two measures indeed appear to contain the same information.

\section{$5 \quad$ Empirical Results}

Figure 4 provides visually suggestive evidence that the combined liquidity premiums in the TIPS and inflation swap markets temporarily exhibited a dip during the QE2 program. The challenge in identifying the causal effect of the QE program on our measure of liquidity is that there are many potential confounding factors that could also affect liquidity and be incorrectly attributed to the program. Our empirical strategy relies on the identifying assumption that we can adequately control for confounding factors with other observable liquidity-related measures. We employ several strategies to quantify the impact of the program and perform several robustness checks detailed in the following.

\subsection{The Econometric Model}

Throughout this section, the baseline assumption is that the sum of liquidity premiums in TIPS and inflation swaps is determined by the econometric model:

$$
L P_{t}(\tau)=\alpha+\delta D_{t}^{Q E 2}+\sum_{i=0}^{T} X_{t-i}^{\prime}(\tau) \beta_{i}+\varepsilon_{t},
$$

where $L P_{t}(\tau)$ is the sum of the liquidity premiums in the TIPS and inflation swap markets in week $t$ for maturity $\tau$ and $D_{t}^{Q E 2}$ is an indicator that the QE2 program was in effect during week $t .{ }^{18}$ We model the liquidity premium as a linear function of a constant $\alpha$, a vector of

\footnotetext{
${ }^{18}$ We define the QE2 period as beginning the week the program was announced (November 3, 2010) until the week the program was completed (June 30, 2011).
} 
exogenous measures of market liquidity $X_{t}(\tau)$ in week $t$ for maturity range $\tau$, and a stochastic residual $\varepsilon_{t}$. The specification flexibly allows for $T$ lags of the exogenous controls to account for autoregressive persistence across periods. The coefficient of interest in equation (1) is $\delta$, which measures the change in the mean liquidity premium while the QE2 program was in operation.

\subsection{Identification}

Identification of $\delta$ in equation (1) relies on a selection-on-observables strategy. That is, to recover the change in the conditional mean of the liquidity measure due to the QE2 program necessitates the assumption that observations outside of the QE2 program serve as good controls for variation associated with other observable measures of market liquidity. Further, we must assume that our control measures of liquidity are exogenous and unaffected by the program, which is a valid assumption under the null hypothesis that the program had no effect on market liquidity. Formally, OLS estimation of equation (1) recovers the average treatment effect of the program if $\mathbb{E}\left[\varepsilon_{t} \mid X_{t}(\tau)\right]=0$.

Given that our identification relies on a selection-on-observables strategy, it is essential that our control variables capture potential confounding factors. The control measures we include in our analysis are the VIX options-implied volatility index, the HPW measure of market illiquidity, on-the-run Treasury par-yield spreads, and inflation swap bid-ask spreads. ${ }^{19}$ Note that the maturities of the last two variables are chosen to correspond to the maturity of $L P_{t}(\tau)$. We briefly discuss the motivation for each control variable in the following:

$V I X$ - The VIX represents near-term uncertainty about the general stock market as reflected in options on the Standard \& Poor's 500 stock price index and is widely used as a gauge of investor fear and risk aversion. The motivation for including this variable is that elevated economic uncertainty would imply increased uncertainty about the future resale price of any security and therefore could cause liquidity premiums that represent investors' guard against such uncertainty to go up.

HPW Illiquidity Measure - The second control variable we include is a market illiquidity measure introduced by HPW. ${ }^{20}$ Their analysis suggests that this measure is a priced risk factor across several financial markets, which we interpret to imply that it represents an economy-wide illiquidity measure that should affect all financial markets.

On-The-Run Treasury Par-Yield Spreads - The third set of control variables are spreads that are typically associated with liquidity in the Treasury market. We use the yield difference

\footnotetext{
${ }^{19}$ Although significantly correlated with our liquidity premium measure, as also suggested by the analysis of Dittmar et al. (2019), U.S. CDS rates add little explanatory power beyond that of the listed control variables and are therefore not included.

${ }^{20}$ The data are publicly available at Jun Pan's website: https://sites.google.com/site/junpan2/publications.
} 
between seasoned (off-the-run) Treasury securities and the most recently issued (on-the-run) Treasury security of the same maturity. ${ }^{21}$ For each maturity segment in the Treasury yield curve, the on-the-run security is typically the most traded security and therefore penalized the least in terms of liquidity premiums.

IS Bid-Ask Spreads - To account for liquidity effects in the inflation swap market, we include the bid-ask spreads on inflation swap contracts with 5- and 10-year maturities as reported by Bloomberg. The microstructure frictions that such spreads represent could potentially account for part of the variation in our liquidity premium measure and we want to control for that effect. The bid-ask spreads of the inflation swap contracts exhibit reasonable time variation at levels consistent with transaction costs in the inflation swap market reported by Fleckenstein et al. (2014) based on conversations with traders. ${ }^{22}$

Since the last two variables are measured as yield spreads, we refer to them jointly as the spread series in the following.

\subsection{Change in the Conditional Mean}

Our first strategy is to estimate the average effect of the QE2 program on our liquidity premium series through OLS estimation of equation (1). Table 2 reports estimates for different sample periods and specifications. Panels A and B report estimates of the change in the conditional mean of the 5-year and 10-year sum of liquidity premiums, respectively. The columns are grouped by the sample used for estimation with columns (1)-(3) corresponding to the full sample. Columns (4)-(6) are estimated on a sample that excludes weeks associated with the financial crisis (1/1/2008 to 6/30/2009), while columns (7)-(9) additionally exclude all weeks associated with other QE programs (the Fed's first QE program (QE1) and its so-called Maturity Extension Program (MEP) that operated from September 2011 through December 2012). Within each sample grouping, we report three specifications with an increasing number of control measures. Columns (1), (4), and (7) are the same specification and only include an indicator for the QE2 period. Columns (2), (5), and (8) add the VIX volatility measure and the HPW measure as controls. Columns (3), (6), and (9) add the onthe-run spreads for Treasuries and the bid-ask spreads for inflation swaps (both measured at maturities corresponding to the maturity of the dependent variable). All regressions include 8 lags of control variables so that $T=8$ in equation (1), but estimates are not sensitive to

\footnotetext{
${ }^{21}$ We do not construct on-the-run spreads for the TIPS market since Christensen et al. (2012) show that such spreads have been significantly biased in the years following the peak of the financial crisis due to the value of the deflation protection option embedded in the TIPS contract.

${ }^{22}$ We do not include bid-ask spreads for TIPS from Bloomberg since they are implausibly flat before the spring of 2011, leading us to question the validity of the data. Haubrich et al. (2012) report bid-ask spreads for 10-year TIPS, which are higher than the Bloomberg data, in particular around the peak of the financial crisis in the fall of 2008 and early 2009. Unfortunately, their series ends in May 2010 and cannot be used for our analysis.
} 
increases in the number of lags. Standard errors reported are estimated using the Newey and West (1987) heteroskedasticity and autocorrelation robust estimator with a 26-period (half-year) maximum lag.

The estimates of the change in the conditional mean recovered with our econometric model are robust to the inclusion of the control variables and the selection of the sample. Furthermore, they are all significantly different from zero. Controlling for other measures of liquidity, our estimates range from -6 to -11 basis points for the 5-year and 10-year liquidity premiums, depending on the sample period and measures included. Notably a negative change is apparent in all specifications, without controlling for any unobserved measures of liquidity. This could suggest our model could be picking up an anomalous period of lower liquidity premiums that happened to coincide with the launch of the QE2 program. We address this concern below using a randomization inference strategy.

We stress that there are several reasons why we must be very cautious in interpreting our estimates as causal. If there are additional omitted factors that our control variables do not capture that are correlated with the QE2 program, our estimate of $\delta$ will be biased. In order to address these concerns we include a diverse set of control variables. Given the substantial values of the adjusted $R^{2}$ achieved by including them, we believe the likelihood that confounding factors are materially biasing our estimates is small.

Secondly, we might be concerned that the inclusion of certain control measures may result in a "bad controls" problem if the QE2 TIPS purchases caused changes in the control variables. While it is possible that the Fed's participation in financial markets could have broad implications, we argue the VIX and HPW measures capture market liquidity broadly that is less likely to be materially affected by the Fed's QE2 program. The more direct controls based on spreads from the Treasury and IS markets may suffer from a stronger bad controls problem. In this case, estimates from specifications (2), (5), and (8) would be preferable to those in specifications (3), (6), and (9). In the following, we therefore focus on specification (8) that excludes the financial crisis as well as other QE programs from the sample in order to minimize polluting effects from those events, although we stress that our results are robust to using other specifications. 


\begin{tabular}{|c|c|c|c|c|c|c|c|c|c|}
\hline & \multicolumn{3}{|c|}{ Full Sample } & \multicolumn{3}{|c|}{ No Financial Crisis } & \multicolumn{3}{|c|}{$\begin{array}{l}\text { No Financial Crisis } \\
\text { or Other QE Programs }\end{array}$} \\
\hline & (1) & $(2)$ & $(3)$ & $(4)$ & $(5)$ & (6) & $(7)$ & $(8)$ & $(9)$ \\
\hline & \multicolumn{9}{|c|}{ Panel A: Sum of 5-year Liquidity Premiums } \\
\hline$\hat{\delta}(\mathrm{QE} 2)$ & $\begin{array}{l}-17.8^{* * *} \\
\quad(6.8)\end{array}$ & $\begin{array}{c}-8.1^{* * *} \\
(2.4)\end{array}$ & $\begin{array}{l}-10.2^{* * *} \\
\quad(2.6)\end{array}$ & $\begin{array}{c}-7.9^{* *} \\
(3.2)\end{array}$ & $\begin{array}{l}-8.6^{* * *} \\
(2.3)\end{array}$ & $\begin{array}{l}-10.6^{* * *} \\
(2.6)\end{array}$ & $\begin{array}{l}-8.6^{* * *} \\
(2.9)\end{array}$ & $\begin{array}{c}-8.9^{* * *} \\
(2.4)\end{array}$ & $\begin{array}{l}-7.8^{* * *} \\
(2.4)\end{array}$ \\
\hline Adj. $R^{2}$ & 0.03 & 0.86 & 0.88 & 0.05 & 0.48 & 0.54 & 0.10 & 0.35 & 0.37 \\
\hline & \multicolumn{9}{|c|}{ Panel B: Sum of 10-year Liquidity Premiums } \\
\hline$\hat{\delta}(\mathrm{QE} 2)$ & $\begin{array}{l}-12.5^{* * *} \\
(3.7)\end{array}$ & $\begin{array}{c}-7.9^{* * *} \\
(2.6)\end{array}$ & $\begin{array}{l}-10.6^{* * *} \\
(3.2)\end{array}$ & $\begin{array}{l}-8.7^{* * *} \\
(2.2)\end{array}$ & $\begin{array}{l}-8.8^{* * *} \\
(2.1)\end{array}$ & $\begin{array}{c}-6.5^{* * *} \\
(2.4)\end{array}$ & $\begin{array}{l}-8.5^{* * *} \\
(2.5)\end{array}$ & $\begin{array}{c}-9.2^{* * *} \\
(1.8)\end{array}$ & $\begin{array}{c}-5.5^{* *} \\
(2.6)\end{array}$ \\
\hline Adj. $R^{2}$ & 0.04 & 0.64 & 0.67 & 0.11 & 0.11 & 0.14 & 0.13 & 0.27 & 0.37 \\
\hline Controls: & & & & & & & & & \\
\hline + VIX \& HPW & & $\checkmark$ & $\checkmark$ & & $\checkmark$ & $\checkmark$ & & $\checkmark$ & $\checkmark$ \\
\hline + Spreads & & & $\checkmark$ & & & $\checkmark$ & & & $\checkmark$ \\
\hline$N$ & 417 & 409 & 409 & 339 & 331 & 331 & 254 & 246 & 246 \\
\hline
\end{tabular}

Table 2: Estimates of the Change in Conditional Mean during QE2

Panels A and B report OLS estimates of $\delta$ from equation (1) with the 5-year and 10-year sums of the liquidity premiums in TIPS and inflation swaps as the dependent variables. Standard errors are reported in parenthesis and are estimated using the Newey and West (1987) heteroskedasticity and autocorrelation robust estimator. Each column reports a specification for a given sample period. Columns (1)-(3) report results for the full sample (1/1/2005 to $12 / 28 / 2012)$, columns (4)-(6) report results for the full sample excluding weeks associated with the financial crisis $(1 / 1 / 2008$ to 6/30/2009), and columns (7)-(9) report results for the full sample excluding the financial crisis and all other periods associated with QE programs (QE1 and the MEP). Columns (1), (4), and (7) are the same specification and only include an indicator for the QE2 period. Columns (2), (5), and (8) add the VIX volatility measure and the HPW illiquidity measure. Columns (3), (6), and (9) add the on-the-run Treasury par-yield spreads and the bid-ask spreads for inflation swaps of the corresponding maturity. All control variables include 8 lags. Stars indicate levels of statistical significance corresponding to $p$-values less than $0.05\left(^{*}\right), 0.01\left(^{* *}\right)$, and $0.001\left(^{* *}\right)$. 


\subsection{Event-Study Analysis}

To test the ability of the controls to account for confounding variation, we perform an eventstudy analysis by estimating specification (8) in Table 2 including an indicator for each week relative to the week before the QE2 announcement. These are recovered with the specification

$$
L P_{t}(\tau)=\alpha+\sum_{s=-8}^{36} \delta_{s} \mathbf{1}\left[t-t_{0}=s\right]+\sum_{i=0}^{8} X_{t-i}^{\prime}(\tau) \beta_{i}+\varepsilon_{t}
$$

where $t_{0}$ denotes the week before QE2 was announced. We normalize the coefficients relative to that week and plot $\delta_{s}-\delta_{0}, \forall s \in\{-8,-7, \ldots, 36\}$ in Figure 5. The black line indicates point estimates and the dark shaded area are 95 percent confidence intervals with the same Newey-West standard errors as in Table 2. The dark line indicates week zero, the week before November 3, 2010, when QE2 was announced. The dashed lines and lighter shaded area indicate the duration of the QE2 program. Due to our normalization, the coefficient for week zero is zero by construction so that we may read the value of -7 basis points in week 8 of the left panel of Figure 5 as indicating the liquidity premium in that week was 7 basis points lower than the week before the announcement after conditioning on other measures of liquidity.

We might think that the weeks immediately prior to the QE2 announcement represent the best control period since the economic landscape would be the most similar. If the weeks prior to the announcement are in fact good controls, we should observe estimates statistically insignificant from the pre-announcement week. We see this clearly at the 5-year maturity specification with every period being statistically indistinguishable from zero. The 10-year maturity specification is less robust with only 4 of 8 being insignificantly different, but there is no clear trend.

We estimate the impact of the QE2 program in an additional way by comparing the residual variation in the immediate pre-program period to that during the program period. To do so, we estimate the following regression:

$$
L P_{t}(\tau)=\alpha+\delta_{P R E} D_{t}^{P R E}+\delta_{Q E 2} D_{t}^{Q E 2}+\sum_{i=0}^{8} X_{t-i}^{\prime}(\tau) \beta_{i}+\varepsilon_{t}
$$

where $D_{t}^{P R E}=1$ in the 9 weeks prior to the announcement and is zero otherwise. The rest of the variables are identical to the definition in equation (1). Table 3 reports the results of estimating equation (3) using OLS and the same specification (8) in Table 2 where we exclude the financial crisis and other QE program periods. The columns each report estimates for the two maturities and also perform the statistical test that the mean in the pre-period is different from the mean during the program. Both differences are close to the estimate reported in 

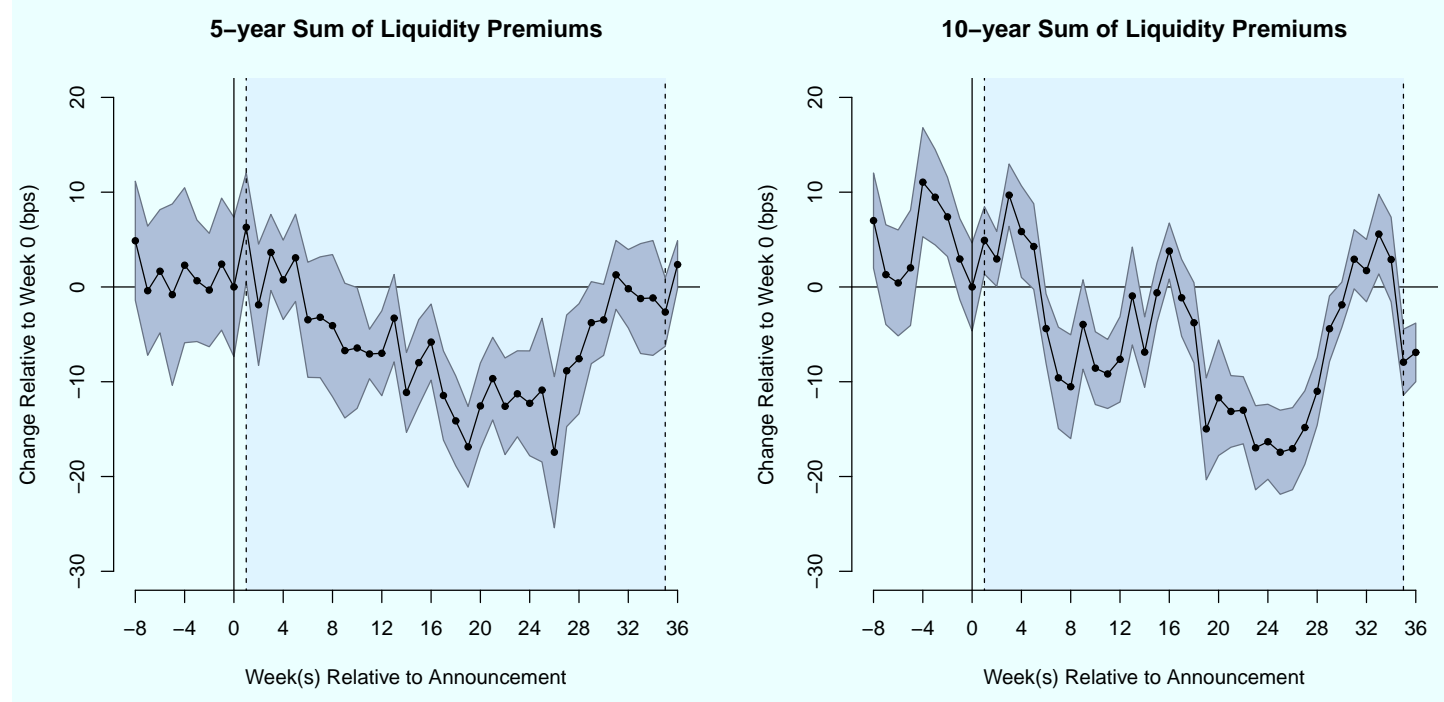

Figure 5: Effect on Sum of Liquidity Premiums following QE2 Announcement

The figure shows estimates for the change in the conditional mean during QE2 estimated using specification (8) in Table 2 decomposed by week relative to the start of the program. The left (right) panel shows the distribution for the 5-year (10-year) sum of liquidity premiums in the TIPS and inflation swap markets. The solid line indicates the week prior to the first week of purchases and the shaded area indicates the time during which the Federal Reserve was actively purchasing TIPS with the dotted lines indicating the first and last week of purchases. Standard errors are reported in parenthesis and are estimated using the Newey and West (1987) heteroskedasticity and autocorrelation robust estimator.

Table 2 indicating a decline of between 8 and 10 basis points. ${ }^{23}$

That said, Figure 5 puts the difference between the actual realization of the liquidity premium and the counterfactual path into sharper focus for the duration of the QE2 program. Interestingly, in both maturity ranges the measure declines during the first third of the program and then increases back to its level at the program start in a fairly symmetric fashion, suggesting financial market participants may have repeatedly priced the liquidity premiums of TIPS and inflation swaps lower for the first half of the program before gradually returning to pre-program levels.

This pattern of dissipating effects as the QE2 program approached its announced end date is consistent with the mechanics of the liquidity channel described in Section 2.2 and shares similarities with the on-the-run premiums in the Treasury market, which also tend to dissipate as the securities go off-the-run and experience significant declines in their liquidity as detailed in Goldreich et al. (2005). As for the absence of an initial change, we speculate that it may have taken an auction or two for investors to assess the extent to which the QE2

\footnotetext{
${ }^{23}$ Coroneo (2018) performs a counterfactual analysis of the effect of the QE2 TIPS purchases on estimated average TIPS liquidity premiums and report positive results consistent with ours.
} 


\begin{tabular}{ccc}
\hline \hline & $\begin{array}{c}5 \text {-year Sum } \\
\text { of Liquidity Premiums }\end{array}$ & $\begin{array}{c}\text { 10-year Sum } \\
\text { of Liquidity Premiums }\end{array}$ \\
\hline$\hat{\delta}^{P R E}$ & -1.4 & 0.9 \\
$(9$-week pre-period) & $(3.5)$ & $(2.5)$ \\
$\hat{\delta}^{Q E 2}$ & $-9.0^{* * *}$ & $-9.2^{* * *}$ \\
$($ QE2 period) & $(2.7)$ & $(1.8)$ \\
& & \\
$\hat{\delta}^{Q E 2}-\hat{\delta}^{P R E}$ & $-7.6^{* *}$ & $-10.0^{* * *}$ \\
$($ change $)$ & $(2.5)$ & $(2.7)$ \\
& & \\
\hline Observations & 246 & 0.27 \\
Adjusted $\mathrm{R}^{2}$ & 0.35 & \\
\hline
\end{tabular}

Table 3: Event-Study Estimates of the Change in Conditional Mean during QE2 The top panel reports OLS estimates from the specification in equation (3) for the 5-year and 10-year sums of the liquidity premiums in TIPS and inflation swaps in the left and right columns, respectively. Standard errors are reported in parenthesis and are estimated using the Newey and West (1987) heteroskedasticity and autocorrelation robust estimator. We exclude the financial crisis and all other periods associated with QE programs (QE1 and the MEP) from the sample. We control for the VIX volatility measure and the HPW illiquidity measure with 8 lags in each variable. We also report the difference in the estimated $\delta^{P R E}$ and $\delta^{Q E 2}$ coefficients with the associated standard errors. Stars indicate levels of statistical significance corresponding to $p$-values less than $0.05\left(^{*}\right), 0.01\left(^{* *}\right)$, and $\left.0.001{ }^{* * *}\right)$.

TIPS purchases would affect sellers' bargaining power in the TIPS market. In that case, the full effect of the liquidity channel may not have been priced in up front as suggested by our results.

\subsection{Robustness of Specification}

Given the clear change in the conditional mean without the inclusion of any control measures, we explore the robustness of our estimates to specification bias. That is, the period in which the Federal Reserve enacted QE2 may have been anomalously more negative than other periods. To test this hypothesis, we perform a randomization inference exercise that randomly assigns a "placebo" treatment period of equal length as QE2 to the sample and delivers an estimate of the effect of these random programs. Specifically, for one placebo estimate we replace the $D_{t}^{Q E 2}$ in equation (1) with an indicator equal to one for the consecutive 34week period beginning at the start of the placebo program and estimate $\hat{\delta}$. Under the null hypothesis that the effect of the program was zero, we can then construct a $p$-value from this set of $\hat{\delta}$ estimates that indicates how likely it would have been to observe our QE2 estimates by chance alone. 

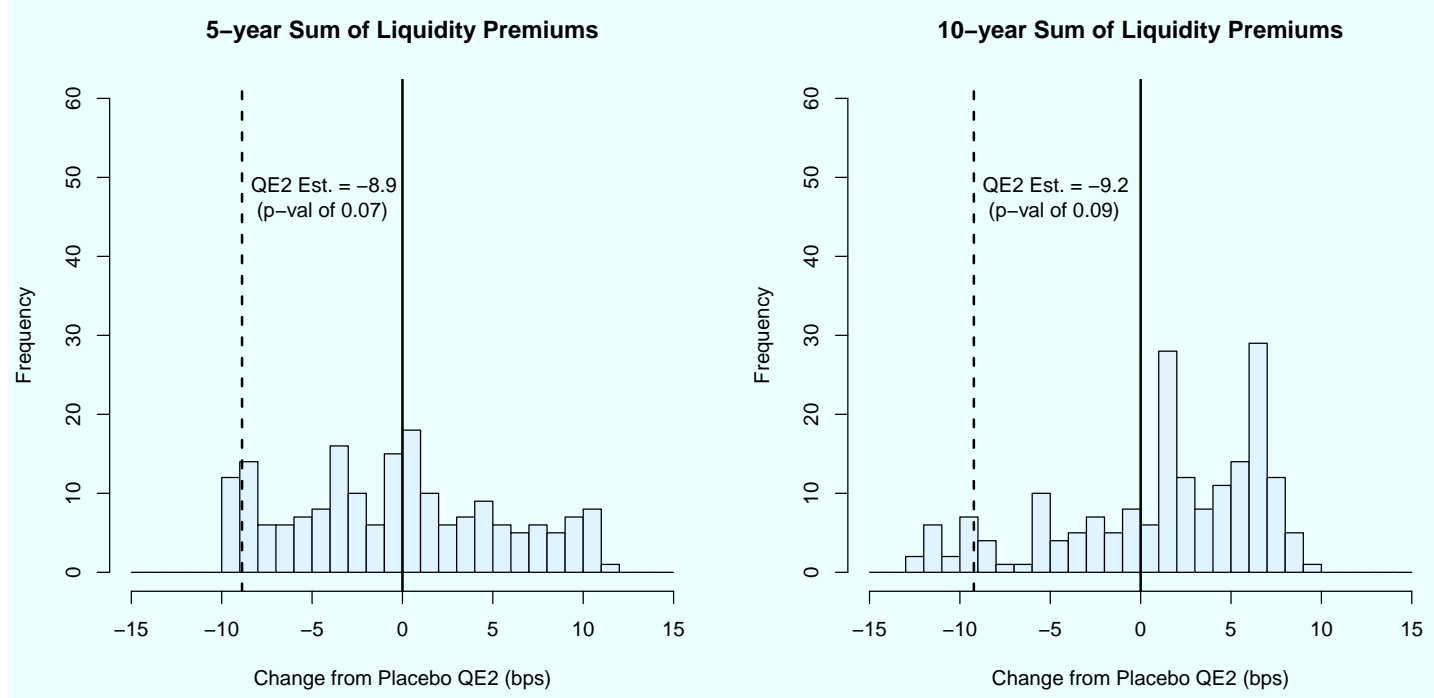

Figure 6: Results from Randomization Inference Exercise

The figure shows the distribution of estimates from specification (8) in Table 2 for the change in the conditional mean for "placebo" periods of the same length as QE2. The left (right) panel shows the distribution for the 5-year (10-year) sum of liquidity premiums in TIPS and inflation swaps. Each distribution is composed of 188 estimates with the estimate for the true program period shown by the dotted line.

We perform the exercise using our preferred specification (8) that excludes the financial crisis and other QE program periods from the sample and includes the VIX and HPW measures with 8 lags. Given our exclusion of various periods, we run a simulation for each period where a sequential set of weeks equal to the length of the QE2 program exists. This results in 188 simulated programs.

Figure 6 shows the results of the randomization inference exercise by plotting the distribution of $\hat{\delta}$ 's with each observation representing a placebo estimate. The left panel plots the results for the 5-year measure and the right panel the results for the 10-year measure. The distributions are roughly centered around zero and is consistent with the null hypothesis with means of -0.4 and 0.8 basis points for the 5-year and 10-year measures, respectively. Our estimates for the actual program are indicated by vertical dotted lines in each panel. They lie at the left tail of the distributions and are more negative than 93 percent of the estimates for the 5-year measure and 91 percent of the estimates of the 10-year measure. This indicates that if a program of zero effect had randomly been assigned to the sample period, it would be fairly unlikely to observe the large negative estimates we recover. We believe this provides evidence that it is unlikely that model error is driving our results. 


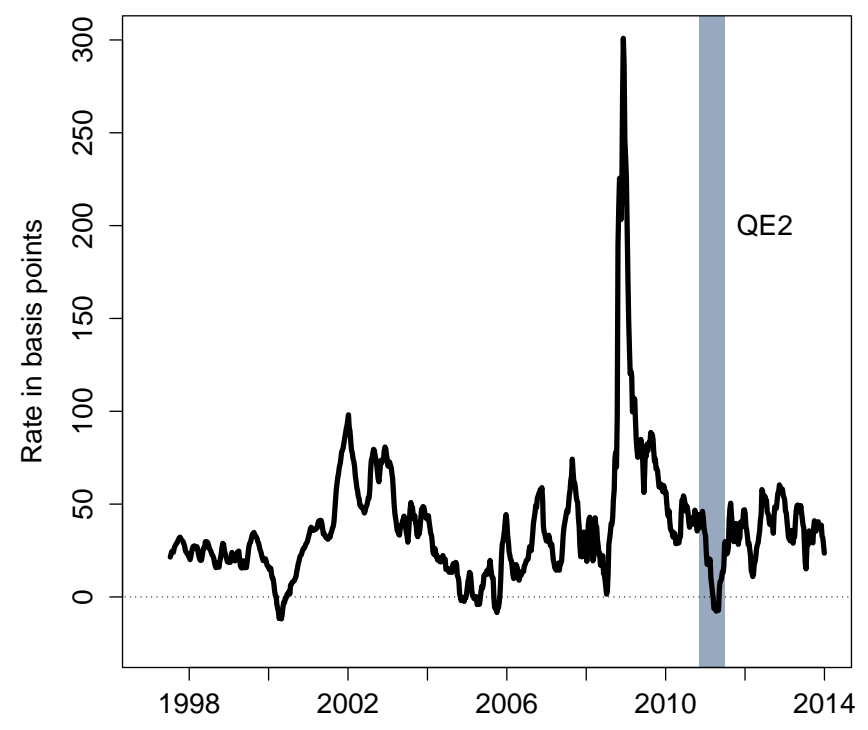

Figure 7: Estimated TIPS Liquidity Premiums

\subsection{Robustness Check with Estimated TIPS Liquidity Premiums}

Our main analysis described so far is based on a model-free measure of the sum of frictions in the TIPS and inflation swap markets relative to the Treasury market. The key advantage of this approach is that it only requires a minimum set of assumptions to be valid. The drawback is twofold. First and most importantly, it is not identified whether the effects documented thus far derive from a reduction in TIPS liquidity premiums or from reduced frictions in inflation swap rates, which complicates the interpretation of our results and the mapping to the liquidity channel of QE discussed in Section 2. Second, our sample is limited to start in 2005 when the inflation swap data becomes available.

To address these two issues, we repeat the core of our analysis using a direct measure of TIPS liquidity premiums. Specifically, we consider the average estimated TIPS liquidity premium reported in a recent paper by Andreasen et al. (2018, henceforth ACR), who augment an existing model of nominal and real yields described in Christensen et al. (2010) with a factor to measure the liquidity premium in TIPS prices. The factor structure is supposed to capture the idea that the amount of outstanding securities locked up in buy-and-hold investors' portfolios and hence unavailable for trading grows over time and affects the liquidity premium of individual securities. To estimate the model and identify the liquidity factor, ACR use weekly historical prices for the entire universe of 5- and 10-year TIPS issued since the inception of the TIPS market in 1997 until December 2013. The average of the estimated 
TIPS liquidity premiums at each point in time produces the series shown in Figure 7. We note that the series averages 38 basis points and is quite volatile with spikes following September 11, 2001, and around the peak of the financial crisis. Also, it exhibits a pronounced temporary dip during the QE2 program similar to the one visible in Figure 4. Despite the similarity it is important to stress that this series is generated by a completely different method based on a dynamic term structure model in combination with directly observable prices for TIPS. Hence, it serves as a very strong robustness check of our previous findings, and because it is solely derived from TIPS prices, it can dispel any concerns that our earlier results were driven mainly by variation in the priced frictions of inflation swaps.

Table 4 reports the results of running the OLS regression in equation (1) with the ACR TIPS liquidity premium series as the dependent variable. We note that, since the inflation swap bid-ask spread series is not available back to 1997, we perform the exercise with only three controls, namely the VIX, the HPW, and the 10-year on-the-run Treasury par-yield spread.

The results show that there is a significant negative change in the conditional mean of the ACR TIPS liquidity premium series during the QE2 program period, when we run the regressions without any controls. When we include controls and exclude the financial crisis as well as other QE programs, the estimates of $\delta$ are smaller and tend to be less significant. However, for our benchmark specification (8) with the VIX and HPW as controls, the estimate remains statistically significantly negative at the 5 percent confidence level and suggests that TIPS liquidity premiums in the 5- to 10-year maturity range were temporarily reduced by about 15 basis points.

One explanation for deviations in the magnitudes between this exercise and our earlier results could be tied to the construction of the GSW TIPS yields that may smooth out frictions in the underlying TIPS prices that the ACR model is specifically designed to capture.

To summarize our findings, we think that we have provided overwhelming evidence that liquidity premiums in the TIPS and inflation swap markets were temporarily significantly reduced during the operation of the QE2 program. Given the robustness of this finding and the sensibleness of the controls used, we feel comfortable concluding that these results did not come about by accident, rather they were a direct consequence of the TIPS purchases included in the QE2 program. Finally, the magnitudes and dynamic profile of the estimated effects seem to align well with the mechanics of the liquidity channel we put forward as a potential transmission channel of QE to long-term interest rates. 


\begin{tabular}{|c|c|c|c|c|c|c|c|c|c|}
\hline & \multicolumn{3}{|c|}{ Full Sample } & \multicolumn{3}{|c|}{ No Financial Crisis } & \multicolumn{3}{|c|}{$\begin{array}{l}\text { No Financial Crisis } \\
\text { or other QE Programs }\end{array}$} \\
\hline & (1) & $(2)$ & $(3)$ & $(4)$ & $(5)$ & (6) & (7) & (8) & (9) \\
\hline$\hat{\delta}(\mathrm{QE} 2)$ & $\begin{array}{l}-24.10^{* *} \\
(8.81)\end{array}$ & $\begin{array}{l}-12.11 \\
(6.60)\end{array}$ & $\begin{array}{c}-15.46^{*} \\
(6.55)\end{array}$ & $\begin{array}{c}-18.75^{*} \\
(7.72)\end{array}$ & $\begin{array}{c}-16.18^{*} \\
(6.96)\end{array}$ & $\begin{array}{c}-15.63^{*} \\
(7.24)\end{array}$ & $\begin{array}{c}-16.61^{*} \\
(8.02)\end{array}$ & $\begin{array}{c}-14.66^{*} \\
(7.02)\end{array}$ & $\begin{array}{l}-12.04 \\
(7.43)\end{array}$ \\
\hline $\begin{array}{l}\text { Controls: } \\
\text { + VIX \& HPW } \\
\text { + On-the-run spread }\end{array}$ & & $\checkmark$ & $\begin{array}{l}\checkmark \\
\checkmark\end{array}$ & & $\checkmark$ & $\begin{array}{l}\checkmark \\
\checkmark\end{array}$ & & $\checkmark$ & $\begin{array}{l}\checkmark \\
\checkmark\end{array}$ \\
\hline$N$ & 774 & 774 & 774 & 696 & 696 & 696 & 559 & 559 & 559 \\
\hline Adj. $R^{2}$ & 0.02 & 0.61 & 0.62 & 0.03 & 0.22 & 0.22 & 0.03 & 0.30 & 0.30 \\
\hline
\end{tabular}

Table 4: Estimates of the Change in Conditional Mean of the ACR TIPS Liquidity Premium during QE2

The table reports OLS estimates of $\delta$ from equation (1) with the ACR TIPS liquidity premium as the dependent variable. Standard errors are reported in parenthesis and are estimated using the Newey and West (1987) heteroskedasticity and autocorrelation robust estimator. Each column reports a specification for a given sample period. Columns (1)-(3) report results for the full sample (1/1/2005 to 12/28/2012), columns (4)-(6) report results for the full sample excluding weeks associated with the financial crisis (1/1/2008 to 6/30/2009), and columns (7)-(9) report results for the full sample excluding the financial crisis and all other periods associated with QE programs (QE1 and the MEP). Columns (1), (4), and (7) are the same specification and only include an indicator for the QE2 period. Columns (2), (5), and (8) add the VIX volatility measure and the HPW illiquidity measure. Columns (3), (6), and (9) add the 10-year on-the run Treasury spread. All control variables include 8 lags. Stars indicate levels of statistical significance corresponding to $p$-values less than $0.05\left({ }^{*}\right), 0.01\left(^{* *}\right)$, and $0.001\left(^{* * *}\right)$. 
Still, one caveat regarding the causality implications of our results is worth noting. We cannot entirely exclude the possibility that the Fed introduced QE2 because liquidity premiums were perceived to be too high. In that case, some reversion might have been expected regardless of the effect of the program. However, given that neither our liquidity premium measure nor the ACR estimated TIPS liquidity premiums are particularly elevated in the run up to QE2, we consider this interpretation to be unlikely.

To shed more light on the workings and limitations of the liquidity channel, we end the section by analyzing whether the QE2 program had any effects on TIPS trading volumes and corporate bond credit spreads.

\subsection{Effects of QE2 on Other Outcomes}

In this section, we estimate the effect of QE2 on other measures of market functioning in order to better characterize the full effect of the program and the underlying mechanism. Specifically, we estimate the effect of QE2 on TIPS trading volumes and AAA-rated U.S. industrial corporate bond credit spreads using the same econometric model as in equation (1) except replacing the dependent variable with the new outcomes of interest.

For the TIPS trading volume exercise, the dependent variable is the weekly average of the daily trading volume in the secondary market for TIPS as reported by the Federal Reserve Bank of New York. ${ }^{24}$ We use the eight-week moving average to smooth out short-term volatility. As with our identification strategy above, we control for other sources of variation in liquidity to measure the effect of the QE2 program.

We also study whether the effects from the liquidity channel extend beyond the targeted securities, which in the case of QE2 were Treasuries and TIPS. To do so, we examine highly rated industrial corporate bond credit spreads and our hypothesis is that the liquidity channel should have no effect as the Fed did not buy any corporate bonds and financial market participants knew this. The dependent variable in this exercise is the excess yield of AAArated U.S. industrial corporate bonds over comparable Treasury yields. ${ }^{25}$ In choosing the maturity, we face a trade-off. On one side, we would ideally like to match the maturity of our liquidity premium measure to be consistent with the previous analysis. However, the credit risk of even AAA-rated industrial bond issuers cannot be deemed negligible at a 5- to 10-year horizon. On the other hand, if we focus on very short-term debt where the credit risk is entirely negligible, we are far from the desired maturity range. We believe using the 2-year credit spread strikes a reasonable balance, and the results are not sensitive to this particular choice. As the credit risk component of such highly rated shorter-term corporate bond yields is minimal, the yield spread largely reflects the premium bond investors require for being

\footnotetext{
${ }^{24}$ The trading volume data are available at: http://www.newyorkfed.org/markets/statrel.html.

${ }^{25}$ The corporate bond yield data are from Bloomberg; see Christensen et al. (2014) for details.
} 


\begin{tabular}{|c|c|c|c|c|c|c|c|c|}
\hline & \multicolumn{4}{|c|}{ TIPS Trading Volume } & \multicolumn{4}{|c|}{ AAA Credit Spread } \\
\hline & \multicolumn{2}{|c|}{ No Financial Crisis } & \multicolumn{2}{|c|}{$\begin{array}{l}\text { No Financial Crisis } \\
\text { or other QE Programs }\end{array}$} & \multicolumn{2}{|c|}{ No Financial Crisis } & \multicolumn{2}{|c|}{$\begin{array}{c}\text { No Financial Crisis } \\
\text { or other QE Programs }\end{array}$} \\
\hline & $(1)$ & $(2)$ & $(3)$ & (4) & $(5)$ & (6) & $(7)$ & (8) \\
\hline$\hat{\delta}(\mathrm{QE} 2)$ & $\begin{array}{c}0.4 \\
(0.6)\end{array}$ & $\begin{array}{c}0.3 \\
(0.4)\end{array}$ & $\begin{array}{c}0.9 \\
(0.6)\end{array}$ & $\begin{array}{c}\text { A: Estimate } \\
0.3 \\
(0.2)\end{array}$ & $\begin{array}{c}\text { Condit } \\
-4.2 \\
(2.7)\end{array}$ & $\begin{array}{l}\text { Mean } \\
-1.1 \\
(2.4)\end{array}$ & $\begin{array}{l}-5.2 \\
(2.9)\end{array}$ & $\begin{array}{l}-2.4 \\
(2.7)\end{array}$ \\
\hline $\begin{array}{l}\text { Controls: } \\
\text { + VIX \& } \\
\text { HPW } \\
\text { + Spreads }\end{array}$ & $\checkmark$ & $\begin{array}{l}\checkmark \\
\checkmark\end{array}$ & $\checkmark$ & $\begin{array}{l}\checkmark \\
\checkmark\end{array}$ & $\checkmark$ & $\begin{array}{l}\checkmark \\
\checkmark\end{array}$ & $\checkmark$ & $\begin{array}{l}\checkmark \\
\checkmark\end{array}$ \\
\hline $\begin{array}{l}\text { Adj. } \mathrm{R}^{2} \\
N\end{array}$ & $\begin{array}{l}0.45 \\
331\end{array}$ & $\begin{array}{l}0.60 \\
331\end{array}$ & $\begin{array}{l}0.30 \\
246\end{array}$ & $\begin{array}{l}0.72 \\
246\end{array}$ & $\begin{array}{l}0.36 \\
289\end{array}$ & $\begin{array}{l}0.37 \\
289\end{array}$ & $\begin{array}{l}0.38 \\
246\end{array}$ & $\begin{array}{l}0.40 \\
246\end{array}$ \\
\hline
\end{tabular}

Table 5: QE2 Response of TIPS Trading Volume and AAA Credit Spreads

The table reports the results of regressing the eight-week moving average of the weekly TIPS trading volume series and the excess yield of AAA-rated U.S. industrial corporate bonds over comparable Treasury yields on specification (1) with the VIX and HPW measures as control variables with 8 lags. Columns (1)-(4) report results for the trading volume and (5)-(8) results for the AAA credit spread. The sample used in estimation is shown at the top of the columns with (1), (2), (5), and (6) corresponding to the sample without the financial crisis and (3), (4), (7), and (8) corresponding to the sample that also excludes other QE programs. The AAA credit spread regressions are also limited by the fact that the series we use is only reported through March 9, 2012. We report Newey-West standard errors with 26 lags.

exposed to the lower trading volume and larger bid-ask spreads in the corporate bond market vis-à-vis the liquid Treasury bond market.

Table 5 reports the results of the estimates of the change in conditional mean during the QE2 program for samples that do not include the financial crisis and those that also exclude other QE programs. The estimates are positive for the TIPS trading volume, but insignificant for all specifications. The AAA credit spreads appear to have a negative change during the course of the program, but are also insignificant. These findings suggest that it is indeed priced frictions and expectations thereof, i.e., the value of liquidity, more so than actual liquidity measured as trading volumes that is affected by the operation of QE programs. Furthermore, there appears to be at most small positive spill-over effects on the priced frictions of nontargeted securities consistent with our description of the liquidity channel.

\section{Conclusion}

In this paper, we argue that one channel of transmission for central bank large-scale asset purchases to long-term interest rates comes about through a reduction of the priced frictions 
in the targeted security classes.

For evidence we analyze the effects the TIPS purchases included in the Fed's QE2 program had on the functioning of the market for TIPS and the related market for inflation swaps. To quantify the frictions in the markets for these two types of financial claims, we use a modelindependent measure of the sum of liquidity premiums in TIPS yields and inflation swap rates constructed from the difference between inflation swap rates and BEI. This measure is ideal for our purposes as it is unaffected by how the QE2 program and its implementation might have changed investors' expectations for economic fundamentals such as inflation and monetary policy.

Our results from regressions with a switch in the conditional mean and related placebo treatment tests both suggest that the TIPS purchases temporarily reduced liquidity premiums in the markets for TIPS and inflation swaps. Specifically, our event-study analysis with weekly indicator variables demonstrates that the purchases persistently depressed the liquidity premium measure by an average of about 10 basis points for the duration of the QE2 program from what we would otherwise have expected it to be. In our view, this represents a considerable reduction. Furthermore, and critical to our interpretation, the liquidity premium effects dissipated towards the end of the QE2 TIPS purchases. This leads us to conclude that one benefit of QE programs is to improve financial market functioning by reducing liquidity premiums through a liquidity channel. However, our results also show the limitation of such liquidity effects in that they appear to only be sustained as long as QE purchases are ongoing and expected to continue. Furthermore, such liquidity effects appear, indeed, to be limited to the targeted securities as we find no significant effects on the liquidity premiums of AAA-rated U.S. industrial corporate bonds.

In an attempt to identify local supply effects in individual TIPS prices from the QE2 TIPS purchases, we adapted the approach of DK. However, our analysis did not yield any significant results. The interpretation we offer for this finding is that the liquidity effects we document are general in nature and not tied to any specific TIPS, which would make them go undetected in the analysis of DK. Clearly, a better understanding of the connection between the liquidity effects we document and potential local supply effects would be desirable, but we leave it for future research. Furthermore, we find that reductions in the priced frictions are not accompanied by improvements in actual liquidity as measured by TIPS trading volumes. Thus, more research is needed to better understand the nature and mechanics of the liquidity channel we unveil in this paper.

Still, our findings could have important policy implications. On a practical note, for understanding BEI and the underlying variation in investors' inflation expectations during the QE2 program, it is crucial to account for the effects we document associated with the liquidity channel. Second, for central banks in countries with somewhat illiquid sovereign bond 
markets, QE programs targeting sovereign debt could be quite effective in lowering liquidity premiums in addition to any benefits arising from other transmission channels. More generally, it appears that even relatively modest QE programs could have large effects if the targeted security classes are illiquid. Thus, the significance of the liquidity channel could matter for the design of QE programs; time frame, purchase pace, and targeted security classes would all be variables that could make a meaningful difference for the effectiveness of a $\mathrm{QE}$ program provided liquidity premiums in the targeted securities are of nontrivial magnitude.

As a final thought, we note that the QE program launched by the European Central Bank in January 2015 could provide rich cross-country data for studying questions related to the liquidity channel highlighted in this paper thanks to the length, size, and implementation of that particular QE program. We encourage others to undertake this research in the future. 


\section{References}

Abrahams, Michael, Tobias Adrian, Richard K. Crump, Emanuel Moench, and Rui Yu, 2016, "Decomposing Real and Nominal Yield Curves," Journal of Monetary Economics, Vol. $84,182-200$.

Andreasen, Martin M., Jens H. E. Christensen, and Simon Riddell, 2018, "The TIPS Liquidity Premium," Working Paper 2017-11, Federal Reserve Bank of San Francisco.

Bauer, Michael D. and Glenn D. Rudebusch, 2014, "The Signaling Channel for Federal Reserve Bond Purchases," International Journal of Central Banking, Vol. 10, No. 3, 233-289.

Brunnermeier, Markus K. and Lasse Heje Pedersen, 2009, "Market Liquidity and Funding Liquidity," Review of Financial Studies, Vol. 22, No. 6, 2201-2238.

Campbell, John Y., Robert J. Shiller, and Luis M. Viceira, 2009, "Understanding InflationIndexed Bond Markets," Brookings Papers on Economic Activity, Spring, 79-120.

Chakraborty, Indraneel, Itay Goldstein, and Andrew MacKinlay, 2017, "Monetary Stimulus and Bank Lending," Manuscript, Wharton School.

Christensen, Jens H. E., 2008, "The Corporate Bond Credit Spread Puzzle," Federal Reserve Bank of San Francisco, Economic Letter 2008-10.

Christensen, Jens H. E. and James M. Gillan, 2012, "Do Fed TIPS Purchases Affect Market Liquidity?" Federal Reserve Bank of San Francisco, Economic Letter 2012-07.

Christensen, Jens H. E. and Signe Krogstrup, 2018, "A Portfolio Model of Quantitative Easing," Working Paper 2016-12, Federal Reserve Bank of San Francisco.

Christensen, Jens H. E. and Signe Krogstrup, 2019, "Transmission of Quantitative Easing: The Role of Central Bank Reserves," Economic Journal, Vol. 129, No. 617, 249-272.

Christensen, Jens H. E., Jose A. Lopez, and Glenn D. Rudebusch, 2010, "Inflation Expectations and Risk Premiums in an Arbitrage-Free Model of Nominal and Real Bond Yields," Journal of Money, Credit and Banking, Supplement to Vol. 42, No. 6, 143-178.

Christensen, Jens H. E., Jose A. Lopez, and Glenn D. Rudebusch, 2012, "Extracting Deflation Probability Forecasts from Treasury Yields," International Journal of Central Banking, Vol. 8, No. 4, 21-60. 
Christensen, Jens H. E., Jose A. Lopez, and Glenn D. Rudebusch, 2014, "Do Central Bank Liquidity Facilities Affect Interbank Lending Rates?" Journal of Business and Economic Statistics, Vol. 32, No. 1, 136-151.

Christensen, Jens H. E. and Glenn D. Rudebusch, 2012, "The Response of Interest Rates to U.S. and U.K. Quantitative Easing," Economic Journal, Vol. 122, F385-F414.

Collin-Dufresne, Pierre, Robert S. Goldstein, and J. Spencer Martin, 2001, "The Determinants of Credit Spread Changes," Journal of Finance, Vol. 56, No. 6, 2177-2207.

Coroneo, Laura, 2018, "TIPS Liquidity Premium and Quantitative Easing," Manuscript, University of York, Department of Economics and Related Studies.

D'Amico, Stefania, Roger Fan, and Yuriy Kitsul, 2018, "The Scarcity Value of Treasury Collateral: Repo-Market Effects of Security-Specific Supply and Demand Factors," Journal of Financial and Quantitative Analysis, Vol. 53, No. 5, 2103-2129.

D’Amico, Stefania, Don H. Kim, and Min Wei, 2018, "Tips from TIPS: The Informational Content of Treasury Inflation-Protected Security Prices," Journal of Financial and Quantitative Analysis, Vol. 53, No. 1, 243-268.

D'Amico, Stefania and Thomas B. King, 2013, "The Flow and Stock Effects of Large-Scale Treasury Purchases: Evidence on the Importance of Local Supply," Journal of Financial Economics, Vol. 108, No. 2, 275-564.

De Pooter, Michiel, Robert F. Martin, and Seth Pruitt, 2018, "The Liquidity Effects of Official Bond Market Intervention," Journal of Financial and Quantitative Analysis, Vol. 53, No. 1, 243-268.

Dittmar, Robert F., Alex Hsu, Guillaume Roussellet, and Peter Simasek, 2019, "Default Risk and the Pricing of U.S. Sovereign Bonds," Georgia Tech Scheller College of Business Research Paper No. 18-20.

Driessen, Joost, Theo E. Nijman, and Zorka Simon, 2016, "The Missing Piece of the Puzzle: Liquidity Premiums in Inflation-Indexed Markets," Manuscript. Department of Finance, Tilburg University.

Dudley, William C., Jennifer Roush, and Michelle Steinberg Ezer, 2009, "The Case for TIPS: An Examination of the Costs and Benefits," Federal Reserve Bank of New York Economic Policy Review, Vol. 15, No. 1, 1-17.

Duffie, Darrell, Nicolae Gârleanu, and Lasse Heje Pedersen, 2007, "Valuation in Over-theCounter Markets," Review of Financial Studies, Vol. 20, No. 5, 1865-1900. 
Eser, Fabian and Bernd Schwaab, 2016, "Evaluating the Impact of Unconventional Monetary Policy Measures: Empirical Evidence from the ECB's Securities Markets Programme," Journal of Financial Economics, Vol. 119, No. 1, 147-167.

Fleckenstein, Mathias, Francis A. Longstaff, and Hanno Lustig, 2014, "The TIPS-Treasury Bond Puzzle," Journal of Finance, Vol. 69, No. 5, 2151-2197.

Fleming, Michael J. and Neel Krishnan, 2012, "The Microstructure of the TIPS Market," Federal Reserve Bank of New York Economic Policy Review, Vol. 18, No. 1, 27-45.

Fleming, Michael J. and John R. Sporn, 2013, "Trading Activity and Price Transparency in the Inflation Swap Market," Federal Reserve Bank of New York Economic Policy Review, Vol. 19, No. 1, 45-57.

Gagnon, Joseph, Matthew Raskin, Julie Remache, and Brian Sack, 2011, "Large-Scale Asset Purchases by the Federal Reserve: Did They Work?," International Journal of Central Banking, Vol. 7, No. 1, 3-43.

Goldreich, David, Bernd Hanke, and Purnendu Nath, 2005, "The Price of Future Liquidity: Time-Varying Liquidity in the U.S. Treasury Market," Review of Finance, Vol. 9, 1-32.

Gürkaynak, Refet S., Brian Sack, and Jonathan H. Wright, 2007, "The U.S. Treasury Yield Curve: 1961 to the Present," Journal of Monetary Economics, Vol. 54, No. 8, 22912304 .

Gürkaynak, Refet S., Brian Sack, and Jonathan H. Wright, 2010, "The TIPS Yield Curve and Inflation Compensation," American Economic Journal: Macroeconomics, Vol. 2, No. $1,70-92$.

Hancock, Diana and Wayne Passmore, 2011, "Did the Federal Reserve's MBS Purchase Program Lower Mortgage Rates?," Journal of Monetary Economics, Vol. 58, 498-514.

Hattori, Masazumi, Andreas Schrimpf, and Vladyslav Sushko, 2016, "The Response of Tail Risk Perceptions to Unconventional Monetary Policy," American Economic Journal: Macroeconomics, Vol. 8, No. 2, 111-136.

Haubrich, Joseph, George Pennacchi, and Peter Ritchken, 2012, "Inflation Expectations, Real Rates, and Risk Premia: Evidence from Inflation Swaps," Review of Financial Studies, Vol. 25, No. 5, 1588-1629.

Hu, Grace Xing, Jun Pan, and Jiang Wang, 2013, "Noise as Information for Illiquidity," Journal of Finance, Vol. 68, No. 6, 2341-2382. 
Kandrac, John, 2013, "Have Federal Reserve MBS Purchases Affected Market Functioning?," Economics Letters, Vol. 121, 188-191.

Kandrac, John, 2018, "The Costs of Quantitative Easing: Liquidity and Market Functioning Effects of Federal Reserve MBS Purchases," International Journal of Central Banking, Vol. 14, No. 5, 259-304.

Kandrac, John and Bernd Schlusche, 2013, "Flow Effects of Large-Scale Asset Purchases," Economics Letters, Vol. 121, 330-335.

Krishnamurthy, Arvind and Annette Vissing-Jorgensen, 2011, "The Effects of Quantitative Easing on Interest Rates: Channels and Implications for Policy," Brookings Papers on Economic Activity, Fall 2011, 215-265.

Lou, Dong, Yan Hongjun, and Jinfan Zhang, 2013, "Anticipated and Repeated Shocks in Liquid Markets," Review of Financial Studies, Vol. 26, No. 8, 1890-1912.

Newey, Whitney K. and Kenneth D. West, 1987, "A Simple, Positive Semi-definite, Heteroskedasticity and Autocorrelation Consistent Covariance Matrix," Econometrica, vol. 55, No. 3, 703-708.

Pasquariello, Paolo, 2018, "Government Intervention and Arbitrage," Review of Financial Studies, Vol. 31, No. 9, 3344-3408.

Pflueger, Carolin E. and Luis M. Viceira, 2016, "Return Predictability in the Treasury Market: Real Rates, Inflation, and Liquidity," Chapter 10 in Pietro Veronesi (ed.) Handbook of Fixed-Income Securities, Wiley, NJ.

Sack, Brian and Robert Elsasser, 2004, "Treasury Inflation-Indexed Debt: A Review of the U.S. Experience," Federal Reserve Bank of New York Economic Policy Review, Vol. 10, No. 1, 47-63.

Svensson, Lars E. O., 1995, "Estimating Forward Interest Rates with the Extended NelsonSiegel Method," Quarterly Review, No. 3, Sveriges Riksbank, 13-26. 


\title{
Online Appendix
}

\section{Does Quantitative Easing Affect Market Liquidity?}

\author{
Jens H. E. Christensen \\ Federal Reserve Bank of San Francisco \\ jens.christensen@sf.frb.org \\ and \\ James M. Gillan \\ Amazon Web Services \\ james.gillan@berkeley.edu
}

The views in this paper are solely the responsibility of the authors and should not be interpreted as reflecting the views of the Federal Reserve Bank of San Francisco or the Board of Governors of the Federal Reserve System.

This version: November 19, 2019. 


\section{Contents}

A TIPS Bid-Ask Spreads 2

B Event Study of QE2 Announcement Effects 3

C Local Supply Effects of QE2 in the TIPS Market $\quad 4$

D Regression Analysis with QE Program Indicator Variables $\quad 9$

$\begin{array}{ll}\text { E Comparison to Asset Swap Spreads } & 12\end{array}$ 


\section{Appendix}

This online appendix document contains all appendices referenced in the paper.

\section{A TIPS Bid-Ask Spreads}

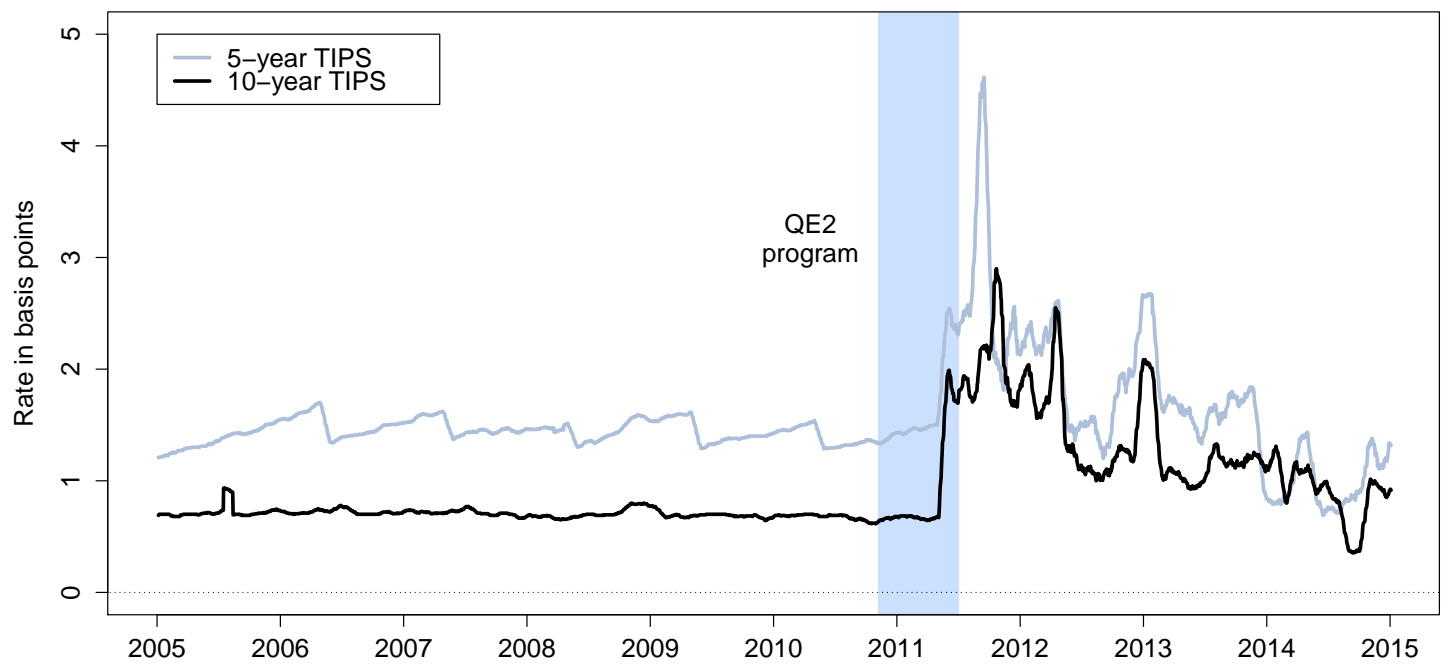

Figure 1: TIPS Bid-Ask Spreads

Figure 1 shows the four-week moving average of the bid-ask spread series for on-the-run 5- and 10-year TIPS, that is, we are tracking the bid-ask spread of the most recently issued 5and 10-year TIPS at each point in time and then piece these series together to get a consistent measure across time. It is clear that the available TIPS bid-ask spread series sourced from Bloomberg are stale with little variation from 2005 until April 2011. This evidence leads us to exclude the TIPS bid-ask spread series from the analysis. 


\section{B Event Study of QE2 Announcement Effects}

\begin{tabular}{|l|l|c|c|c|c|c|c|}
\hline \multicolumn{2}{|c|}{ Response } & \multicolumn{7}{|c|}{ Maturity } \\
\cline { 3 - 8 } & Nov. 2, 2010 & 122 & 159 & 195 & 227 & 256 & 282 \\
\hline \hline \multirow{3}{*}{ Nominal yields } & Nov. 3, 2010 & 118 & 156 & 192 & 227 & 258 & 286 \\
\cline { 3 - 8 } & Change & $\mathbf{- 4}$ & $\mathbf{- 3}$ & $\mathbf{- 2}$ & $\mathbf{0}$ & $\mathbf{2}$ & $\mathbf{4}$ \\
\hline \hline \multirow{3}{*}{ TIPS yields } & Nov. 2, 2010 & -28 & -9 & 10 & 27 & 41 & 54 \\
& Nov. 3, 2010 & -33 & -12 & 8 & 26 & 42 & 56 \\
\cline { 2 - 8 } & Change & $\mathbf{- 5}$ & $\mathbf{- 4}$ & $\mathbf{- 2}$ & $\mathbf{- 1}$ & $\mathbf{0}$ & $\mathbf{2}$ \\
\hline \hline \multirow{3}{*}{ TIPS BEI rates } & Nov. 2, 2010 & 150 & 168 & 185 & 201 & 215 & 227 \\
& Nov. 3, 2010 & 151 & 168 & 185 & 201 & 216 & 230 \\
\cline { 2 - 8 } & Change & $\mathbf{1}$ & $\mathbf{0}$ & $\mathbf{0}$ & $\mathbf{1}$ & $\mathbf{1}$ & $\mathbf{2}$ \\
\hline \hline \multirow{3}{*}{ Inflation swap rates } & Nov. 2, 2010 & 183 & 199 & 216 & 228 & 238 & 251 \\
& Nov. 3, 2010 & 185 & 199 & 215 & 229 & 237 & 248 \\
\cline { 2 - 8 } & Change & $\mathbf{2}$ & $\mathbf{0}$ & $\mathbf{- 1}$ & $\mathbf{1}$ & $\mathbf{- 1}$ & $\mathbf{- 3}$ \\
\hline \hline \multirow{3}{*}{ LP measure } & Nov. 2, 2010 & 32 & 32 & 31 & 28 & 23 & 23 \\
& Nov. 3, 2010 & 34 & 31 & 30 & 28 & 21 & 18 \\
\cline { 2 - 8 } & Change & $\mathbf{2}$ & $\mathbf{0}$ & $\mathbf{- 1}$ & $\mathbf{0}$ & $\mathbf{- 2}$ & $\mathbf{- 6}$ \\
\hline
\end{tabular}

Table 1: Market Response to QE2 Announcement

The table reports the one-day response of nominal Treasury yields, real TIPS yields, TIPS breakeven inflation, inflation swap rates, and the LP measure at six maturities to the announcement of QE2 on November 3, 2010. All numbers are measured in basis points and reported in continuously compounded equivalents. The Treasury and TIPS yields are from Gürkaynak et al. (2007, 2010), while the inflation swap rates are downloaded from Bloomberg.

Table 1 summarizes the market reaction to the announcement of the QE2 program on November 3, 2010, using a one-day event window. The key observation is the rather muted response of medium- and long-term Treasury and TIPS yields. Importantly for our analysis, this converts into an even more muted response of TIPS breakeven inflation and inflation swap rates that leave the liquidity premium measure little affected. To put the reported yield changes into perspective, we note that the standard deviation of daily changes in the LP measure over the period from January 4, 2005, to November 2, 2010, is 5.4 basis points at the 5 -year maturity and declines monotonically with maturity reaching 4.0 basis points at the 10-year maturity. We take this as evidence that there are no statistically significant effects related to the announcement of the QE2 program that need to be accounted for. 


\section{Local Supply Effects of QE2 in the TIPS Market}

In this appendix, we describe our adaptation of the analysis of D'Amico and King (2013, henceforth DK) to attempt to identify local supply effects in the TIPS market.

The results presented in the main text suggest that the QE2 TIPS purchases led to a sustained reduction in the frictions to trading in the markets for TIPS and inflation swaps. However, the exact channel through which the effects came about is not identified. At face value, the purchases could have lowered liquidity premiums in both markets. Alternatively, if there are local supply effects from the purchases, this would tend to push down TIPS yields, while nominal yields and inflation swap rates presumably would be unaffected in that case. As a consequence, BEI would widen leading to a decline in our liquidity premium measure. In this appendix, to shed light on this latter alternative channel, we attempt to estimate any direct effects on TIPS prices from the QE2 TIPS purchases by replicating the approach of DK.

Assuming the purchased securities are held for a considerable period of time, QE purchases are effectively equivalent to a reduction in the available stock of the targeted securities. The empirical question is whether fluctuations in the supply of government debt should affect yields. Under the expectations hypothesis and in standard term structure models, such supply effects are ruled out. However, models with imperfect asset substitutability or preferred-habitat investors allow for local supply effects on bond yields (see DK for a detailed discussion). Still, as is evident from Figure 2, which shows the changes in the 5- and 10-year Treasury and TIPS yields around the time of the QE2 program, the naked eye is a poor guide for detecting such supply effects as both nominal and real yields increased on net during the QE2 program, but the latter less than the former causing BEI to widen as well. Thus, a statistical model is needed to tease out any effects from the asset purchases against this backdrop of generally rising yields. By using security-level data one might hope to be able to identify local supply effects and how they vary across securities with different maturities and liquidity characteristics. To do so, we replicate the approach of DK as briefly summarized in the following. However, we note up front that, unlike the analysis in the main text, the key element in their approach is to control appropriately for changes in expectations about monetary policy and other economic fundamentals that may affect TIPS prices independent of QE2. Below we will discuss the complications this may entail.

First, we introduce notation and define the fundamental statistical objects, which are as 


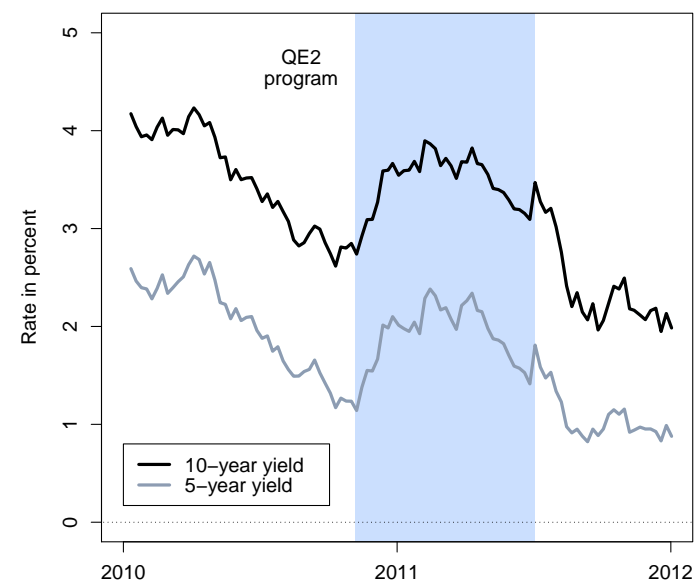

(a) Treasury yields

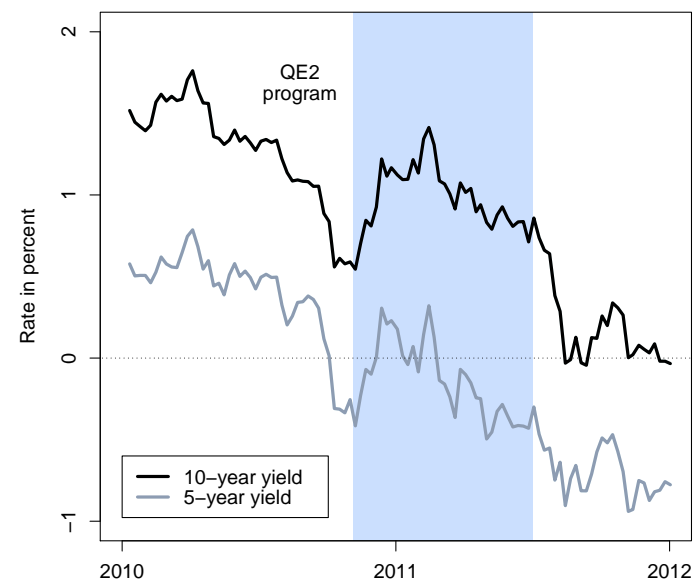

(b) TIPS yields

Figure 2: Treasury and TIPS Yields

Panel (a) illustrates the 5- and 10-year Treasury yields from the Gürkaynak et al. (2007) database over the 2010-2011 period. Panel (b) illustrates the 5- and 10-year TIPS yields from the Gürkaynak et al. (2010) database over the same period.

follows:

(i) $N$ is the total number of TIPS in existence during the QE2 program.

(ii) $O^{n}(t)$ equals the notional amount of security $n$ outstanding at $t, n \in\{1, \ldots, N\}$.

(iii) $Q^{n}(t)$ equals the dollar amount of security $n$ purchased at $t, n \in\{1, \ldots, N\}$.

(iv) $R^{n}(t)=\frac{P^{n}(t)-P^{n}(t-1)}{P^{n}(t-1)}$ is the daily percentage price change of security $n$ at time $t$, $n \in\{1, \ldots, N\}$.

(v) $T^{n}$ is the maturity date of security $n, n \in\{1, \ldots, N\}$.

The second step is to calculate the variables used in the subsequent regressions. Similar to DK, for each security $n$, we define buckets of substitutes, but limit the number to three buckets due to the smaller number of TIPS trading relative to the number of securities in the market for regular Treasuries.

The first bucket is denoted $S_{0}(n)$ and only contains security $n$. For this bucket, two variables are defined:

(i) $O_{0}^{n}(t)=O^{n}(t)$ is the notional amount of security $n$ outstanding. 
(ii) $Q_{0}^{n}(t)=Q^{n}(t)$ is the amount of security $n$ purchased at time $t$.

The second bucket is denoted $S_{1}(n)$ and contains all securities with maturities within two years of the maturity of security $n$, that is, $S_{1}(n)=\left\{m:\left|T^{m}-T^{n}\right| \leq 2\right\}$. Following DK we refer to these securities as the near substitutes for security $n$.

Finally, the third bucket is denoted $S_{2}(n)$ and contains all securities with a difference in maturity of more than two years relative to the maturity of security $n$, that is, $S_{2}(n)=\{m$ : $\left.\left|T^{m}-T^{n}\right|>2\right\}$. Again, using language similar to DK, we refer to these securities as the far substitutes for security $n$.

Related to the last two buckets, the following variables are defined:

(i) $O_{i}^{n}(t)=\sum_{m \in S_{i}(n)} O^{m}(t)$ is the notional amount outstanding of bucket $i$ substitutes for security $n$ at time $t, i \in\{1,2\}$.

(ii) $Q_{i}^{n}(t)=\sum_{m \in S_{i}(n)} Q^{m}(t)$ is the amount of bucket $i$ substitutes for security $n$ purchased at time $t, i \in\{1,2\}$.

As in DK, we use normalized variables in the regressions:

(i) $q_{0}^{n}(t)=\frac{Q_{0}^{n}(t)}{O_{0}^{n}(t)+O_{1}^{n}(t)}$ is the amount of security $n$ purchased at time $t$ relative to the notional amount outstanding of security $n$ itself and its near substitutes.

(ii) $q_{i}^{n}(t)=\frac{Q_{i}^{n}(t)}{O_{0}^{n}(t)+O_{1}^{n}(t)}$ is the amount of bucket $i$ substitutes for security $n$ purchased at time $t$ relative to the notional amount outstanding of security $n$ itself and its near substitutes, $i \in\{1,2\}$.

Finally, similar to DK, we run regressions of the daily percentage price change of each TIPS security on a set of variables:

$$
R^{n}(t)=\gamma_{0} q_{0}^{n}(t)+\gamma_{1} q_{1}^{n}(t)+\gamma_{2} q_{2}^{n}(t)+\delta(t)+\alpha^{n}+\varepsilon^{n}(t)
$$

where

- $\gamma_{0}$ is security $n$ 's price elasticity to own purchases;

- $\gamma_{1}$ is security $n$ 's price elasticity to purchases of near substitutes;

- $\gamma_{2}$ is security n's price elasticity to purchases of far substitutes; 


\begin{tabular}{lccc}
\hline Purchases & All TIPS & $\begin{array}{c}<10 \text { years to } \\
\text { maturity }\end{array}$ & $\begin{array}{c}>10 \text { years to } \\
\text { maturity }\end{array}$ \\
\hline Own & -0.023 & 0.080 & -0.035 \\
& $(-0.83)$ & $(0.950)$ & $(-1.990)$ \\
Near substitutes & -0.068 & -0.068 & -0.036 \\
$\quad$ (maturity w/in 2 years of own) & $(-1.470)$ & $(-0.910)$ & $(-1.100)$ \\
Far substitutes & 0.008 & 0.001 & 0.004 \\
$\quad$ (maturity more than 2 years from own) & $(0.560)$ & $(0.030)$ & $(0.460)$ \\
& & & \\
\# Obs. & 427 & 284 & 143 \\
\# CUSIPs & 30 & 20 & 10 \\
Adjusted $R^{2}$ & 0.733 & 0.762 & 0.953 \\
\hline
\end{tabular}

Table 2: Flow Effects on Day of Purchase

The table reports the results of regressions of the flow effects from the QE2 TIPS purchases as described in the text. The first column reports the results of using all available TIPS with more than two years to maturity, while the following two columns report the result of splitting that sample into one subsample for TIPS with between two and ten years to maturity, and one subsample for TIPS with more than ten years to maturity. T-statistics are reported in parentheses. Asterisks * and ** indicate significance at the 5 percent and 1 percent levels, respectively.

- $\delta(t)$ represents time fixed effects;

- $\alpha^{n}$ represents security fixed effects.

It is worth noting that we drop all TIPS with less than two years remaining to maturity at the beginning of the QE2 program because TIPS near maturity have rather erratic price behavior due to the seasonality and general unpredictability of shocks to the headline consumer price index. ${ }^{1}$

Table 2 reports the regression results for the full sample using all available TIPS with more than 2 years to maturity as well as the results from two subsamples, one for TIPS with between 2 and 10 years to maturity, the other for TIPS with more than 10 years to maturity. ${ }^{2}$ We note that all estimated purchase elasticities are insignificant and frequently do not even have the right sign. In short, we are not able to detect any local supply effects in TIPS prices directly.

Various explanations could account for this outcome. First, as emphasized by DK, according to the theory of local supply effects in bond markets (see Vayanos and Vila 2009), they are more likely to matter when liquidity and market functioning is poor, that is, when the

\footnotetext{
${ }^{1}$ For similar reasons, TIPS with less than two years to maturity are discarded in the construction of the Gürkaynak et al. (2010) TIPS yield curve.

${ }^{2}$ We split the sample around the 10-year maturity point as there is a discrete jump in TIPS outstanding with remaining maturity above 10 years, as can also be seen in Figure 2(b) in the paper.
} 
arbitrageurs who trade away profit opportunities along the yield curve are capital constrained and are taking on only the most profitable trades, not necessarily all available arbitrages. As noted in Figure 3 in the paper, our measure of TIPS and inflation swap market functioning had reached pre-crisis levels well before the announcement of the QE2 program. Thus, it is indeed possible that market functioning could have been restored and local supply effects would be small for that reason. ${ }^{3}$ In addition, we think that there are issues with the specification of the time fixed effects represented by $\delta(t)$. This specification provides a poor proxy for changes in the shape of the yield curve on purchase dates. For example, a level shift in the TIPS yield curve will affect the prices of long-maturity TIPS in a very different way than the prices of short-maturity TIPS. ${ }^{4}$ By contrast, the time fixed effect imposes an identical price response across all TIPS. Furthermore, the bias from this misspecification might be more severe in our case than in the analysis of DK for two reasons. First, our pool of TIPS is smaller and more heterogeneous than their sample of regular Treasuries that is dominated by securities with three to ten years remaining to maturity. ${ }^{5}$ Second, the limited number of purchase dates in our analysis could matter as well since it allows for less averaging of any errors induced by the misspecified time fixed effects.

To summarize, we believe there are compelling reasons why we are not able to identify any purchase effects on individual TIPS prices from the QE2 TIPS purchases using the approach of DK. One key difference is that our approach based on the liquidity premium measure is unaffected by changes in expectations about economic fundamentals, unlike the method used by DK, which could be severely biased by them. Furthermore, our results suggest that the QE2 TIPS purchase operations led to a reduction in the general frictions to trading in the market for TIPS and the related market for inflation swaps that may not be tied to any specific TIPS. Finally, the liquidity effects we detect are persistent and not limited to a few days around each TIPS purchase operation. Hence, they may go undetected in the approach used by DK that relies on day-to-day variation for its identification.

\footnotetext{
${ }^{3}$ Using an approach similar to DK, Kandrac and Schlusche (2013) analyze the effects of Treasury securities purchases on Treasury bond prices in all the Fed's QE programs. They find that effects do appear to fade in the later programs.

${ }^{4}$ Figure 2(b) shows that the TIPS curve did experience several level shifts during the QE2 program.

${ }^{5}$ The closer securities are in terms of maturity, the smaller is the room for error from the misspecification of the time fixed effects.
} 


\section{Regression Analysis with QE Program Indicator Variables}

As a preliminary exercise, we run regressions with our liquidity premium measure described in Section 4 of the paper as the dependent variable on the set of control variables detailed in Section 5 of the paper. Specifically, we consider the VIX, the illiquidity measure introduced by $\mathrm{Hu}$ et al. (2013, henceforth HPW), the on-the-run premium of newly issued U.S. Treasury bonds over equivalent seasoned Treasuries, and the bid-ask spreads of inflation swap contracts. As in the paper, we run regressions with our liquidity premium measure at the 5 - and 10-year maturity. In the 5-year regressions, we use data for the on-the-run premium and inflation swap bid-ask spreads measured at the 5-year maturity. Similarly, in the 10-year regressions, we use data for the on-the-run premium and inflation swap bid-ask spreads measured at the 10-year maturity.

In addition, we follow Hancock and Passmore (2015) and include indicator variables for the duration of each of the Fed's four major asset purchase programs executed between November 2008 and October 2014. The purpose is to detect whether there are any unusual sustained deviations in our liquidity premium measure from its historical statistical relationship with the set of control variables during the operation of each asset purchase program. The start date and end date of the four programs are as follows. The initial announcement related to the Fed's first QE program, denoted QE1, was made on November 25, 2008, and that program ended on March 31, 2010. As described in the paper, the Fed's second QE program, referred to as QE2, was announced on November 3, 2010, and operated until June 30, 2011. The Fed's Maturity Extension Program (MEP), also known as "Operation Twist," was introduced on September 21, 2011, and completed on December 31, 2012. Finally, the Treasury bond purchases by the Fed during its third and final QE program, known as QE3, were executed from January 1, 2013 until October 31, 2014. ${ }^{6}$ We stress that all of the above dates are determined based on official FOMC communications and also used in the shading of each program in Figure 3 in the paper. Moreover, we note that the regressions in this appendix are based on an updated sample relative to the analysis in the paper. It contains weekly data from January 7, 2005 to December 30, 2016, a total of 626 observations for each variable.

Table 3 reports the results for the regressions at the 5-year maturity, while Table 4 reports

\footnotetext{
${ }^{6}$ We note that the start date of the QE3 program is ambiguous since the MBS purchases under the program were announced on September 13, 2012, while its Treasury and TIPS purchases only started in 2013. Since our focus is on the latter, we date the start of QE3 to the beginning of 2013.
} 


\begin{tabular}{|c|c|c|c|c|c|c|c|}
\hline Explanatory variables & (1) & $(2)$ & $(3)$ & (4) & $(5)$ & (6) & $(7)$ \\
\hline Intercept & $\begin{array}{c}0.57 \\
(3.69)\end{array}$ & $\begin{array}{l}-7.06 \\
(3.90)\end{array}$ & $\begin{array}{l}-7.74 \\
(4.64)\end{array}$ & $\begin{array}{c}-7.82^{*} \\
(3.85)\end{array}$ & $\begin{array}{l}-7.14 \\
(3.88)\end{array}$ & $\begin{array}{c}-5.12 \\
(4.51)\end{array}$ & $\begin{array}{c}-6.87 \\
(5.28)\end{array}$ \\
\hline VIX & $\begin{array}{l}0.62^{* *} \\
(0.20)\end{array}$ & $\begin{array}{l}0.67^{* *} \\
(0.24)\end{array}$ & $\begin{array}{l}0.67^{* *} \\
(0.22)\end{array}$ & $\begin{array}{l}0.69^{* *} \\
(0.24)\end{array}$ & $\begin{array}{l}0.64^{* *} \\
(0.25)\end{array}$ & $\begin{array}{l}0.63^{* *} \\
(0.24)\end{array}$ & $\begin{array}{l}0.64^{* *} \\
(0.24)\end{array}$ \\
\hline HPW & $\begin{array}{l}6.10^{* *} \\
(0.86)\end{array}$ & $\begin{array}{l}6.17^{* *} \\
(0.87)\end{array}$ & $\begin{array}{l}6.32^{* *} \\
(0.97)\end{array}$ & $\begin{array}{l}6.12^{* *} \\
(0.89)\end{array}$ & $\begin{array}{l}6.34^{* *} \\
(0.99)\end{array}$ & $\begin{array}{l}6.20^{* *} \\
(0.85)\end{array}$ & $\begin{array}{l}6.39^{* *} \\
(1.08)\end{array}$ \\
\hline On-the-run premium & & $\begin{array}{l}-0.95 \\
(0.49)\end{array}$ & $\begin{array}{l}-0.94 \\
(0.50)\end{array}$ & $\begin{array}{l}-1.11^{*} \\
(0.49)\end{array}$ & $\begin{array}{l}-1.07 \\
(0.56)\end{array}$ & $\begin{array}{l}-0.93 \\
(0.49)\end{array}$ & $\begin{array}{l}-1.10^{*} \\
(0.55)\end{array}$ \\
\hline IS bid-ask spread & & $\begin{array}{c}0.90^{*} \\
(0.36)\end{array}$ & $\begin{array}{l}0.99^{* *} \\
(0.37)\end{array}$ & $\begin{array}{l}1.06^{* *} \\
(0.34)\end{array}$ & $\begin{array}{c}0.89^{*} \\
(0.36)\end{array}$ & $\begin{array}{c}0.82^{*} \\
(0.38)\end{array}$ & $\begin{array}{l}1.11^{* *} \\
(0.36)\end{array}$ \\
\hline QE1 indicator & & & $\begin{array}{l}-2.91 \\
(6.00)\end{array}$ & & & & $\begin{array}{l}-4.36 \\
(6.04)\end{array}$ \\
\hline QE2 indicator & & & & $\begin{array}{l}-9.20^{*} \\
(4.39)\end{array}$ & & & $\begin{array}{r}-10.44^{*} \\
(4.60)\end{array}$ \\
\hline MEP indicator & & & & & $\begin{array}{c}2.23 \\
(3.20)\end{array}$ & & $\begin{array}{c}0.37 \\
(3.43)\end{array}$ \\
\hline QE3 indicator & & & & & & $\begin{array}{l}-4.05 \\
(3.79)\end{array}$ & $\begin{array}{l}-4.39 \\
(3.89)\end{array}$ \\
\hline Adjusted $R^{2}$ & 0.79 & 0.81 & 0.82 & 0.81 & 0.81 & 0.81 & 0.82 \\
\hline
\end{tabular}

Table 3: Regression Results for the 5-Year Liquidity Premium Series

The table reports the results of regressions with the 5-year liquidity premium series as the dependent variable and four explanatory variables that represent measures of financial market uncertainty and functioning. In addition, there are indicator variables for the duration of the Fed's four major asset purchase programs as described in the text. Standard errors computed by the Newey-West estimator (with 13 lags) are reported in parentheses. Asterisks ${ }^{*}$ and ${ }^{* *}$ indicate significance at the 5 percent and 1 percent levels, respectively.

the corresponding results for the regressions at the 10-year maturity.

First, we note that the set of control variables are able to explain the variation in our liquidity premium series to a reasonable degree, in particular at the five-year maturity where all four control variables are statistically significant.

As for the indicator variables for the four asset purchase programs, note the very similar effect on both maturities for each asset purchase program. More importantly, QE2 is the only program with a statistically significant coefficient on its indicator variable, and its coefficient is negative and between 9 and 10 basis points in magnitude in all regressions, consistent with the findings in the paper. The estimated coefficients for the indicator variables of the other programs are all insignificant and frequently even with the wrong sign relative to the prediction from the liquidity channel. Still, we note the negative, but insignificant coefficients 


\begin{tabular}{|c|c|c|c|c|c|c|c|}
\hline Explanatory variables & (1) & $(2)$ & $(3)$ & $(4)$ & $(5)$ & (6) & (7) \\
\hline Intercept & $\begin{array}{c}17.84^{* *} \\
(3.88)\end{array}$ & $\begin{array}{c}17.28^{* *} \\
(4.75)\end{array}$ & $\begin{array}{c}16.03^{* *} \\
(4.25)\end{array}$ & $\begin{array}{c}16.06^{* *} \\
(4.47)\end{array}$ & $\begin{array}{c}17.66^{* *} \\
(4.73)\end{array}$ & $\begin{array}{c}18.95^{* *} \\
(5.22)\end{array}$ & $\begin{array}{c}16.60^{* *} \\
(4.35)\end{array}$ \\
\hline VIX & $\begin{array}{l}-0.12 \\
(0.26)\end{array}$ & $\begin{array}{l}-0.09 \\
(0.25)\end{array}$ & $\begin{array}{l}-0.07 \\
(0.21)\end{array}$ & $\begin{array}{l}-0.09 \\
(0.25)\end{array}$ & $\begin{array}{l}-0.13 \\
(0.26)\end{array}$ & $\begin{array}{l}-0.12 \\
(0.25)\end{array}$ & $\begin{array}{l}-0.08 \\
(0.22)\end{array}$ \\
\hline HPW & $\begin{array}{l}3.67^{* *} \\
(0.82)\end{array}$ & $\begin{array}{l}4.30^{* *} \\
(1.06)\end{array}$ & $\begin{array}{l}4.59^{* *} \\
(1.08)\end{array}$ & $\begin{array}{l}4.29^{* *} \\
(1.04)\end{array}$ & $\begin{array}{l}4.34^{* *} \\
(1.05)\end{array}$ & $\begin{array}{l}4.46^{* *} \\
(0.10)\end{array}$ & $\begin{array}{l}4.75^{* *} \\
(1.10)\end{array}$ \\
\hline On-the-run premium & & $\begin{array}{l}-0.20 \\
(0.17)\end{array}$ & $\begin{array}{l}-0.41 \\
(0.27)\end{array}$ & $\begin{array}{l}-0.21 \\
(0.17)\end{array}$ & $\begin{array}{l}-0.17 \\
(0.17)\end{array}$ & $\begin{array}{l}-0.24 \\
(0.18)\end{array}$ & $\begin{array}{l}-0.49 \\
(0.29)\end{array}$ \\
\hline IS bid-ask spread & & $\begin{array}{l}-0.01 \\
(0.42)\end{array}$ & $\begin{array}{c}0.13 \\
(0.41)\end{array}$ & $\begin{array}{c}0.24 \\
(0.36)\end{array}$ & $\begin{array}{l}-0.04 \\
(0.41)\end{array}$ & $\begin{array}{l}-0.13 \\
(0.41)\end{array}$ & $\begin{array}{c}0.25 \\
(0.33)\end{array}$ \\
\hline QE1 indicator & & & $\begin{array}{c}7.32 \\
(8.97)\end{array}$ & & & & $\begin{array}{l}7.40 \\
(9.21)\end{array}$ \\
\hline QE2 indicator & & & & $\begin{array}{c}-9.21^{* *} \\
(3.43)\end{array}$ & & & $\begin{array}{l}-8.95^{*} \\
(3.63)\end{array}$ \\
\hline MEP indicator & & & & & $\begin{array}{c}2.11 \\
(2.16)\end{array}$ & & $\begin{array}{l}-0.41 \\
(2.57)\end{array}$ \\
\hline QE3 indicator & & & & & & $\begin{array}{l}-3.05 \\
(2.83)\end{array}$ & $\begin{array}{l}-3.36 \\
(3.01)\end{array}$ \\
\hline Adjusted $R^{2}$ & 0.49 & 0.49 & 0.50 & 0.51 & 0.49 & 0.49 & 0.52 \\
\hline
\end{tabular}

Table 4: Regression Results for the 10-Year Liquidity Premium Series

The table reports the results of regressions with the 10-year liquidity premium series as the dependent variable and four explanatory variables that represent measures of financial market uncertainty and functioning. In addition, there are indicator variables for the duration of the Fed's four major asset purchase programs as described in the text. Standard errors computed by the Newey-West estimator (with 13 lags) are reported in parentheses. Asterisks ${ }^{*}$ and ${ }^{* *}$ indicate significance at the 5 percent and 1 percent levels, respectively.

for the QE3 indicator variable. Their size of between 3 and 4 basis points is suggestive of a weak liquidity channel effect for this program.

These findings explain our focus on the QE2 program. Given that this program was the largest and most intense in terms of TIPS purchases, it offers the best opportunity to detect evidence of the liquidity channel. However, we stress that this does not rule out the existence of such effects from the Fed's other asset purchase programs. They are just smaller thanks to the less intense TIPS purchases in these programs. This makes their impact harder to distinguish from other confounding factors, as also suggested by our regression results. 


\section{E Comparison to Asset Swap Spreads}

In this appendix, we elaborate on the construction of our liquidity premium measure described in Section 4 of the paper and explain how it relates to the asset swap spreads used in Pflueger and Viceira (2016), which represents an alternative measure of the priced frictions in the TIPS market relative to the Treasury market.

To begin, we believe that assumptions (1) and (2) in Section 4 are uncontroversial because the market for U.S. Treasury bonds is one of the most liquid fixed-income markets. In comparison, TIPS are widely considered to be less liquid. However, assumption (3) that the observed inflation swap rates are above their ideal frictionless rate is less obvious and merits elaboration.

We justify this assumption based on previous research on the mechanics of hedging activity in the inflation swap market. Campbell et al. (2009) suggest that the observed inflation swap rate should be marked up from the unobserved frictionless rate due to the financing and transaction costs of replicating cash flows in related asset swap markets. In practice, there are two main strategies for generating CPI-linked floating cash flows. The first is to buy the TIPS with the desired maturity. This requires funding and implies receiving cash flows on all coupon dates of that security, which investors may not find desirable. The alternative is to enter into a zero-coupon inflation swap of the desired maturity. As its value is zero at inception, there are no funding costs in a zero-coupon inflation swap and investors should be willing to pay a premium for this convenience, which explains why the inflation swap rate can be above BEI in equilibrium. However, the size of the inflation swap rate markup is primarily determined from the supply side. The counterparty to the inflation swap (typically a hedge fund or investment bank) hedges the CPI-linked cash flows by going long in TIPS and short in nominal Treasury bonds through the asset swap market. Thus, the markup represents the compensation the counterparty requires for assuming the liquidity risk of multiple transactions to hedge the contract.

This hedging activity creates a connection between our measure of TIPS and inflation swap liquidity premiums and asset swap rates. In an asset swap, the party who has a long position in the contract pays LIBOR plus a spread while receiving the cash flow of a specific bond without exchange of the principal. In an inflation swap, the party who has a short position in the contract typically generates CPI-linked cash flows by making the following set of transactions at time $t$ to hedge the assumed risk: 
- A short position in the $\tau$-year zero-coupon inflation swap struck at $\widehat{I S}_{t}(\tau)$, that is, the investor will receive $\widehat{I S}_{t}(\tau) \tau$ at maturity in return for delivering the net change in the price level $\frac{C P I(t+\tau)}{C P I(t)}-1$.

- A long asset swap position for the $\tau$-year zero-coupon TIPS, that is, agree to paying $\left[\mathrm{LIBOR}+\beta_{t}^{R}(\tau)\right] \tau$ to receive the fixed accrued coupon $\widehat{y}_{t}^{R}(\tau) \tau$ and the accrued inflation compensation $\frac{C P I(t+\tau)}{C P I(t)}-1 .^{7}$

- A short asset swap position in the $\tau$-year zero-coupon Treasury bond, that is, agree to paying the nominal Treasury yield $\widehat{y}_{t}^{N}(\tau) \tau$ to receive $\left[\operatorname{LIBOR}+\beta_{t}^{N}(\tau)\right] \tau$.

Here, $\beta_{t}^{N}(\tau)$ and $\beta_{t}^{R}(\tau)$ denote the asset swap spreads for the nominal Treasuries and TIPS, respectively. As all transactions involve swaps on zero-coupon assets, there is no outlay upon inception because they all have zero net value and payments are only exchanged at maturity. Table 5 summarizes the outlays and receipts from this set of transactions at maturity. The net receipt to the party who has a short position in the inflation swap is

$$
\left[\widehat{I S}_{t}(\tau)-\left(\widehat{y}_{t}^{N}(\tau)-\widehat{y}_{t}^{R}(\tau)\right)+\beta_{t}^{N}(\tau)-\beta_{t}^{R}(\tau)\right] \tau \geq 0
$$

Note that this strategy is really a hedge as the value on the left-hand side of equation (1) is deterministic and set at the inception of the contract. For the leveraged investor to be willing to participate in the inflation swap market this value must be nonnegative as indicated. Since we define our liquidity premium measure as $L P_{t}(\tau)=\widehat{I S}_{t}(\tau)-\left(\widehat{y}_{t}^{N}(\tau)-\widehat{y}_{t}^{R}(\tau)\right)$, the inequality in equation (1) can also be written as

$$
L P_{t}(\tau)+\beta_{t}^{N}(\tau)-\beta_{t}^{R}(\tau) \geq 0
$$

Campbell et al. (2009) note that, normally, the asset swap spreads are negative and more so for the nominal Treasuries, that is ${ }^{8}$

$$
\beta_{t}^{N}(\tau)<\beta_{t}^{R}(\tau) \leq 0
$$

\footnotetext{
${ }^{7}$ Here, we are neglecting the value of the deflation protection in the TIPS in that the actual payment on the TIPS asset swap is $\max \left[\frac{C P I(t+\tau)}{C P I(t)}-1,0\right]$. We thank Xiaopeng Zhang for pointing this out. Thus, the calculations are accurate provided the value of the deflation protection for the particular TIPS in the asset swap is negligible. If not, they can be corrected by calculating its value in a way similar to the one described in Christensen et al. (2012).

${ }^{8}$ During the financial crisis of 2008 and $2009, \beta_{t}^{R}(\tau)$ turned positive, but the relative relationship between $\beta_{t}^{N}(\tau)$ and $\beta_{t}^{R}(\tau)$ remained as indicated by the first inequality.
} 


\begin{tabular}{|l|c|}
\hline Receipts & $\widehat{I S}_{t}(\tau) \tau+\widehat{y}_{t}^{R}(\tau) \tau+\frac{C P I(t+\tau)}{C P I(t)}-1+\left[\operatorname{LIBOR}+\beta_{t}^{N}(\tau)\right] \tau$ \\
\hline Payments & $\widehat{y}_{t}^{N}(\tau) \tau+\frac{C P I(t+\tau)}{C P I(t)}-1+\left[\operatorname{LIBOR}+\beta_{t}^{R}(\tau)\right] \tau$ \\
\hline \hline Net receipts & {$\left[\widehat{I S}_{t}(\tau)-\left(\widehat{y}_{t}^{N}(\tau)-\widehat{y}_{t}^{R}(\tau)\right)+\beta_{t}^{N}(\tau)-\beta_{t}^{R}(\tau)\right] \tau$} \\
\hline
\end{tabular}

Table 5: Cash Flow of Investment Strategy that Hedges a Short Position in a Zero-Coupon Inflation Swap Contract

Illustration of the cash flows involved in the investment strategy that hedges a short position in an inflation swap. It involves: (1) The inflation swap position itself, (2) a long asset swap position in the $\tau$-year zero-coupon TIPS, and (3) a short asset swap position in the $\tau$-year zero-coupon Treasury bond.

Under competitive circumstances (zero cost of entry to the inflation swap market, etc.), we expect equation (2) to hold with equality. Using the inequality in equation (3), we can then rewrite equation (2) as

$$
L P_{t}(\tau)=\beta_{t}^{R}(\tau)-\beta_{t}^{N}(\tau)>0
$$

Thus, our liquidity premium measure should equal the difference between the TIPS and nominal Treasury asset swap spreads and be strictly positive. Of course, this is an idealized calculation based on zero-coupon bonds, but the difference between asset swap spreads on TIPS and regular Treasuries should still provide a good approximation to our measure.

In Figure 3, we compare the 10-year TIPS-Treasury asset swap spread used in Pflueger and Viceira (2016) to our 10-year liquidity premium measure. ${ }^{9}$ We find that the two measures are highly positively correlated and of approximately the same magnitude as theory would suggest. Unfortunately, this asset swap spread series is only monthly and therefore not useful for our empirical analysis. Still, we note that the series exhibit a temporary drop during the QE2 program with a peak trough in April 2011 that matches well with the variation in our liquidity premium series.

Finally, we stress that, without additional information, any combination of nonnegative $\delta_{t}^{R}(\tau)$ and $\delta_{t}^{I S}(\tau)$ that satisfies the condition $L P_{t}(\tau)=\delta_{t}^{R}(\tau)+\delta_{t}^{I S}(\tau)$ is admissible and cannot be legitimately excluded ex ante. Also, we underscore that our construction is valid for any sample of nominal Treasury and real TIPS yields as long as our three key assumptions are satisfied by the data. This observation implies that the size and shape of our measure depend on the underlying pool of bonds, the method used in the yield curve construction, etc., but

\footnotetext{
${ }^{9}$ We thank Carolin Pflueger for sharing their data.
} 


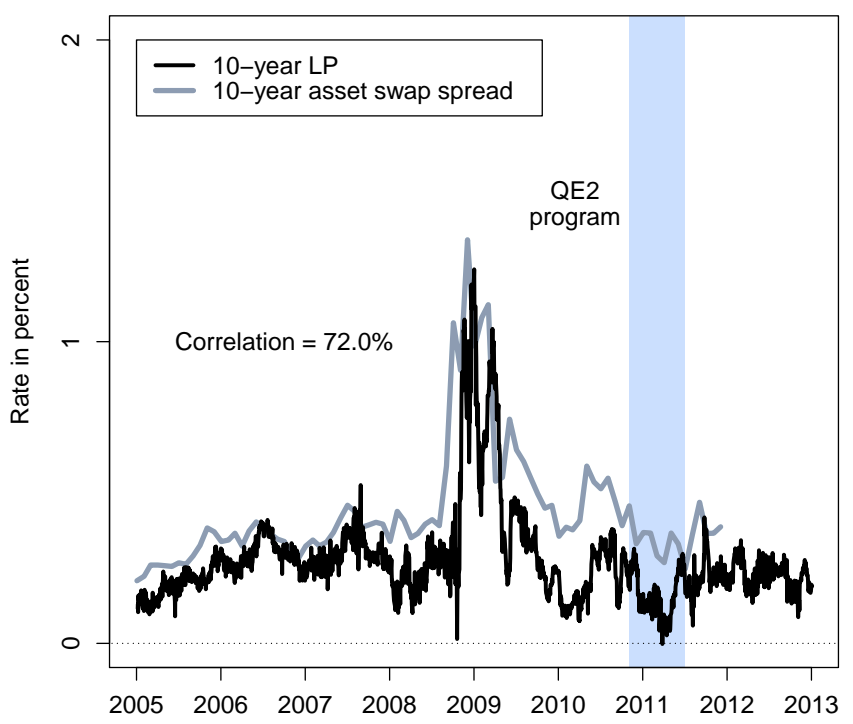

Figure 3: Comparison of Liquidity Premium Measure and Asset Swap Spread

Illustration of the 10-year TIPS and inflation swap liquidity premium measure, which is daily covering the period from January 4, 2005, to December 31, 2012, a total of 1,977 observations. Also shown is the difference between 10-year TIPS and Treasury asset swap spreads used in Pflueger and Viceira (2016), which is a monthly series covering the period January 2005 to December 2011, a total of 84 observations.

that its interpretation remains valid despite such differences. 


\section{References}

Campbell, John Y., Robert J. Shiller, and Luis M. Viceira, 2009, "Understanding InflationIndexed Bond Markets," Brookings Papers on Economic Activity, Spring, 79-120.

Christensen, Jens H. E., Jose A. Lopez, and Glenn D. Rudebusch, 2012, "Extracting Deflation Probability Forecasts from Treasury Yields," International Journal of Central Banking, Vol. 8, No. 4, 21-60.

D'Amico, Stefania and Thomas B. King, 2013, "The Flow and Stock Effects of Large-Scale Treasury Purchases: Evidence on the Importance of Local Supply," Journal of Financial Economics, Vol. 108, No. 2, 275-564.

Gürkaynak, Refet S., Brian Sack, and Jonathan H. Wright, 2007, "The U.S. Treasury Yield Curve: 1961 to the Present," Journal of Monetary Economics, Vol. 54, No. 8, 22912304 .

Gürkaynak, Refet S., Brian Sack, and Jonathan H. Wright, 2010, "The TIPS Yield Curve and Inflation Compensation," American Economic Journal: Macroeconomics, Vol. 2, No. 1, 70-92.

Hancock, Diana and Wayne Passmore, 2015, "How Does the Federal Reserve's Large-Scale Asset Purchases (LSAPs) Influence Mortgage-Backed Securities (MBS) Yields and U.S. Mortgage Rates?," Real Estate Economics, Vol. 43, No. 4, 855-890.

Hu, Grace Xing, Jun Pan, and Jiang Wang, 2013, "Noise as Information for Illiquidity," Journal of Finance, Vol. 68, No. 6, 2341-2382.

Kandrac, John and Bernd Schlusche, 2013, "Flow Effects of Large-Scale Asset Purchases," Economics Letters, Vol. 121, 330-335.

Pflueger, Carolin E. and Luis M. Viceira, 2016, "Return Predictability in the Treasury Market: Real Rates, Inflation, and Liquidity," Chapter 10 in Pietro Veronesi (ed.) Handbook of Fixed-Income Securities, Wiley, NJ.

Vayanos, Dimitri and Jean-Luc Vila, 2009, "A Preferred-Habitat Model of the Term Structure of Interest Rates," NBER Working Paper 15487. 